Portland State University

PDXScholar

Fall 9-24-2014

\title{
Integrating K-W-L Prompts into Science Journal Writing: Can Simple Question Scaffolding Increase Student Content Knowledge?
}

Brandon Joel Wagner

Portland State University

Follow this and additional works at: https://pdxscholar.library.pdx.edu/open_access_etds

Part of the Other Rhetoric and Composition Commons, and the Science and Mathematics Education Commons

Let us know how access to this document benefits you.

\section{Recommended Citation}

Wagner, Brandon Joel, "Integrating K-W-L Prompts into Science Journal Writing: Can Simple Question Scaffolding Increase Student Content Knowledge?" (2014). Dissertations and Theses. Paper 2127. https://doi.org/10.15760/etd.2125

This Thesis is brought to you for free and open access. It has been accepted for inclusion in Dissertations and Theses by an authorized administrator of PDXScholar. Please contact us if we can make this document more accessible: pdxscholar@pdx.edu. 
Integrating K-W-L Prompts into Science Journal Writing: Can Simple Question Scaffolding Increase Student Content Knowledge?

by

Brandon Joel Wagner

A thesis submitted in partial fulfillment of the requirement for the degree of

Master of Science Teaching

in

General Science

Thesis Committee:

Michael Flower, Chair

Melissa Potter

Anita Bright

Portland State University

2014 


\begin{abstract}
Writing-to-learn strategies have been administered in the past to enrich student learning. The purpose of this study was to see if $\mathrm{K}-\mathrm{W}$-L prompts in science journal writing could benefit student content knowledge within biology. Two high school biology classes were provided with learning journals. The journals given to the students during the treatment unit were provided with K-W-L question prompts to guide student learning while during the comparison unit students were given an open ended writing assignment. Pre and posttests were administered to determine student-learning gains. Student motivations and opinions of the treatment were collected through student interviews. The combined results were used to determine to what extent could K-W-L prompts in science journal writing influence comprehension of content knowledge. This study found there to be no difference in student learning gains when utilizing the K-W-L literacy strategy versus another free-writing activity. When scored, student K-W-Ls total scores did correlate to student success on unit tests. This opens up the potential for K-W-Ls to serve as an adequate tool for formative assessment. Here the K-W-L could be expanded to enrich student question asking, potentially aid students learning English, and potentially be used by students without teacher scaffolding.
\end{abstract}




\section{Acknowledgements}

I would like to thank the faculty and staff in the Masters of Science Teaching program at Portland State University for their advice and aid during this entire process. Especially the following: Cary Sneider for guiding my research and taking the time to make suggestions throughout the writing process, Stephanie Wagner for helping me begin this journey and always being there to keep me on track, and Melissa Potter for all the advice and assistance. Without Melissa this project would not be nearly as polished as it is. I would also like to thank Michael Flower for his support and kind words during my defense. A very special thank you goes to Anita Bright from Portland State University's Graduate School of Education for her unwavering positivity and support. For her amazing job on running the statistical analysis, I want to thank Laurie Cremona. For her full support and assistance I would like to thank Kerryn Henderson. Thank you to the participants of this study, without you or Kerryn this research would not be possible. Finally, I would like to thank my parents, Patrick and Paula, for their love and support, Rissa Crozier for proofreading anything I asked her to, and my friends and peers for their words of encouragement. 


\section{Table of Contents}

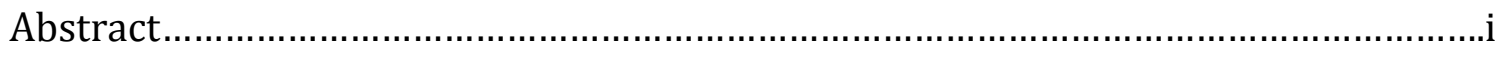

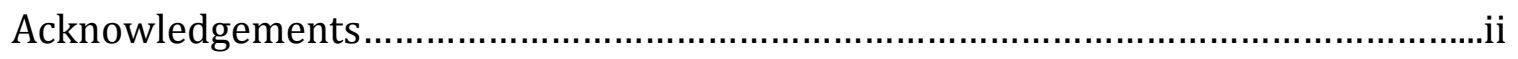

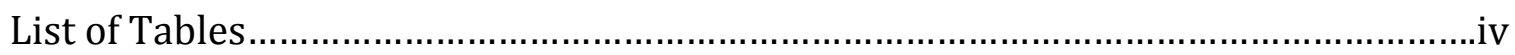

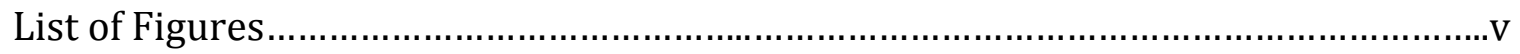

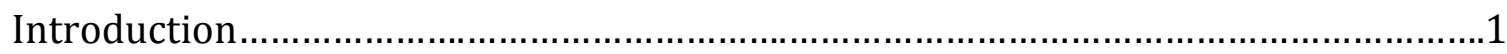

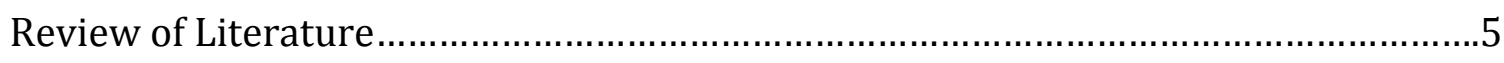

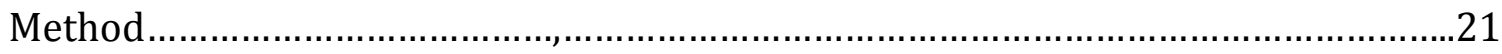

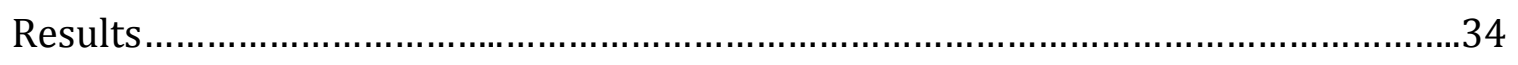

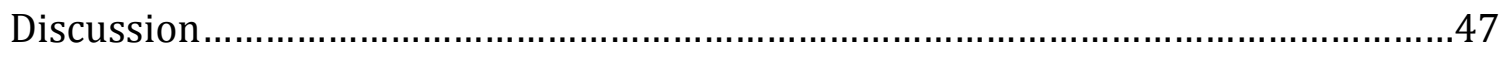

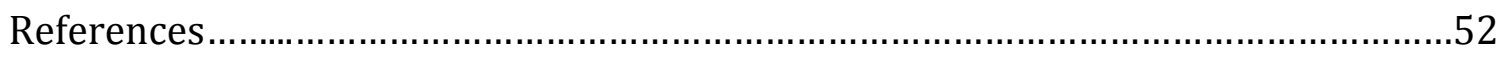

Appendices

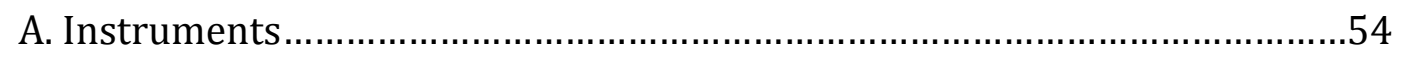

B. Student Work Samples and Responses..............................................59

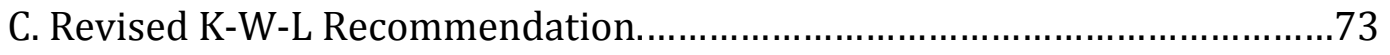

D. Research Approval Documents....................................................... 74 


\section{List of Tables}

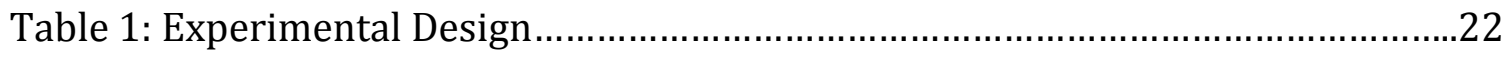

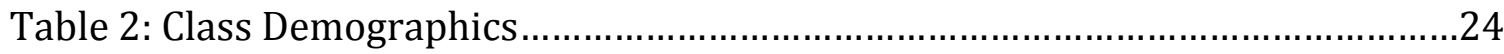

Table 3: Comparison of Pretest Scores of Treatment and Comparison Units for all

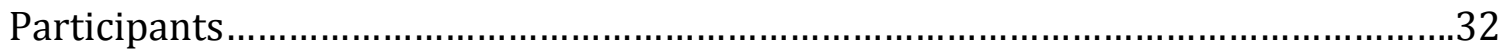

Table 4: Comparison of Learning Gains on Pre and Posttest Scores of Treatment and

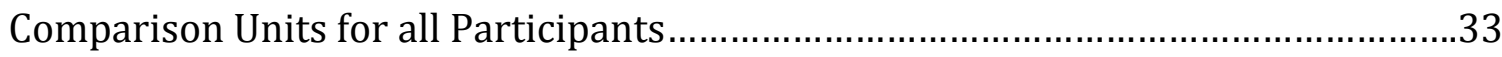

Table 5: Regression Analysis of Treatment Unit...............................................35

Table 6: Regression Analysis of Comparison Unit............................................36

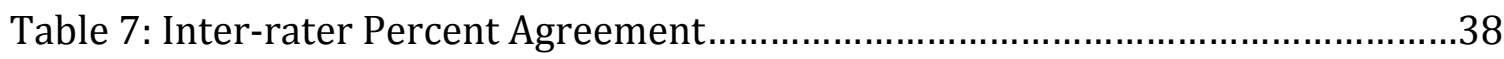

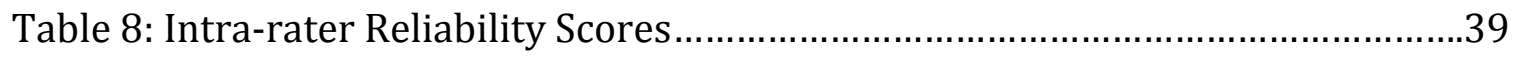




\section{List of Figures}

Figure 1. Previous Student Content Knowledge ...................................................35

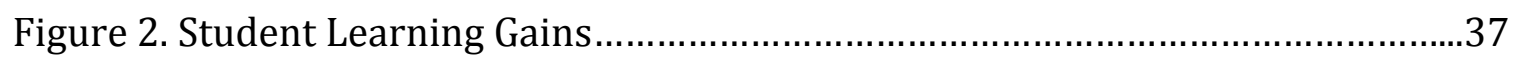




\section{Introduction}

Teaching as an art form has numerous tenets and what seem like infinite philosophies. One piece of powerful imagery is the balancing act instructors must engage in between direct instruction and allowing students to build their own meaning and connections within the subject. The question of to what degree does a teacher take in leading to answers and student reflection appears to be one without a true answer. Every individual is different and may need more or less focused attention. Research has shown that students in different content areas utilize different strategies when interacting with the material (Gogger et al., 2012). Within the sciences, incorporating simple question prompts into writing-to-learn activities may give students a tool to better understand scientific ideas and how they build off previous concepts. Choosing effective scaffolding that is not too intrusive yet adequate to direct reflection and connections is a real challenge.

K-W-L and writing-to-learn strategies have already illustrated their ability to increase student content knowledge in various areas. Typically, K-W-L is a literacy strategy in the form of a graphic organizer that turns the audience into active participants while reading (Ogle, 1986). The K step asks them what previous Knowledge they know about a topic or subject. This allows the reader to engage in a pre thought process so as to be anticipating rather than simply reacting to content (Cantrell \& Fusaro, 2000). The second step, W, asks the reader what further questions they have about the topic or what they Want to learn. Finally the L step encourages readers to reflect on what material they have Learned after being exposed to the reading. Here the reader attempts to answer any of their remaining 
questions and tie the new material to previously learned concepts. When done continuously the process allows the readers to tie subjects and ideas together and create meaning for themselves. This way content does not simply become a disjointed set of informational islands, but a blended mosaic of knowledge.

Biology is much like other scientific fields in that it utilizes its own complex concepts and language, and in order to fully understand those ideas they must be integrated into our previous knowledge base. This affects students in that they must become comfortable in using these ideas and terms within the discipline. Having students write about what they have learned that is directed towards an audience less familiar with the subject matter than the students can facilitate that articulation and understanding of content. Such an approach is likely to be more effective than regurgitating terms to an audience that is merely composed of the instructor (Gunel, Hand, and McDermott, 2008). Students must fully comprehend the material in order to teach others; in this case the students would be tasked to write as if to a peer or another student. Students' learning journals can be formatted in such a way that allows them to take on that role of authority and boil down the big ideas into simple, approachable language (Gunel, Hand, \& McDermott, 2008). It seems possible that viewing journal entrees for quality in this way could lend itself to demonstrating student proficiency.

It is important to note how A Framework for K-12 Science Education (NRC, 2012) and Next Generation Science Standards (NGSS Lead States, 2013) both reinforce the skills of building connections, communicating understanding, and the importance of writing skills. Learning journals are able to bolster those same skills 
through continued writing and help students develop higher order thinking (Hand, Prain, \& Wallace, 2002). Interacting with the material could become easier if the students implement the activity themselves with little continued instructor enforcement, such as potentially seen with the K-W-L format in journal writing.

Providing students with those basic questions will scaffold their learning process and understanding of the content. Over time taking away those prompts after demonstrating their usefulness to students will foster their continued use through student generated questions. Alleviating some of that balance the teacher must go out of their way to maintain self-reflection and metacognition. The idea of incorporating these questions into a journal entry format would hopefully prove useful later within my own instruction. Being able to check each student's level of proficiency and understanding within the content would serve as a version of formal assessment and an opportunity to grant student feedback. This feedback would take on the form of directing student quality and perhaps quantity of journal excerpts, as well as a granting the instructor the opportunity to identify what strategies are working for their students within certain areas of material (Gogger et al., 2012).

This research study attempts to answer the question to what extent can the use of K-W-L prompts in science journal writing increase students' content knowledge? These prompts will give the students adequate direction to focus their thinking on important ideas. Following this format also asks them to consider their understanding of the subjects before and after instruction. Here the journals also act as written bridges to past and future content. Students serve as stewards not only to their own learning, but take up that role to others since their entries are written to 
communicate clearly to individuals unfamiliar with the content. The hypothesis of this study is that science journal writing with K-W-L prompts will lead to an increase in biology content knowledge over unprompted writing strategies. Through writing the student subjects will be experiencing strategies such rehearsing with the material, developing their own way in which to organize it, and elaborating on it for others (Christensen \& McCrindle, 1995). 


\section{Review of Literature}

The review opens by explaining how literacy strategies have been shown to increase student content knowledge and lower student dropout rates in college level science courses by raising student engagement. From here, the articles focus on how journal writing with reflective components can be used to help students identify and use metacognitive and cognitive learning strategies. These reflective writing components and cognitive strategies can be observed in the K-W-L literacy strategy. This transitions into two articles about how writing activities where the students' peers serving as the audience can help increase the demonstration of student knowledge, forcing the students to go into deeper detail about the subject when writing. To conclude the readings are articles describing and outlining the KW-L literacy strategy, as well as its versatility and effectiveness in the classroom environment.

\section{Literacy and Writing-to-Learn Strategies}

Introductory biology courses at the post-secondary level rely primarily on a format of robustly populated lectures, extensive expository written materials, and condensed laboratory activities (Harmon and Pegg 2012). This deluge of biological information and exercises gives the student little time to properly connect these concepts, especially for students lacking a positive attitude, organizational skills, or solid educational background towards the sciences. In order to assuage these student anxieties Harmon and Pegg (2012) set out to incorporate literacy strategies into college level introductory biology lab sections in order improve student's 
understanding of the lecture material. Two lab sections taught by the researchers were exposed to various literacy strategies throughout the semester, while one comparison lab section was given the standard laboratory activity and allowed to proceed without extra engagement with the material. Data from six other lab sections not implementing literacy strategies and that were taught by different teaching assistants were also collected. Literacy strategies used in the treatment groups were concept mapping, focused question writing, developing comparisons charts, vocab etymology, and the sketching of processes as a visual medium. Results were collected through the use of pre and posttests to determine student growth within course content knowledge, the treatment groups were given a survey inquiring about student impressions towards the literacy strategies used, as well as informal interviews. Student dropout rates were also charted for comparison between the treatment and comparisons sections. Test scores of the treatment groups depicted an increase between pre and posttests over the comparison group as well as that of other lab sections taught by different teaching assistants. Average semester grades for the students using the literacy strategies were also higher and dropout rates within the treatment group were also lower than that of the comparison group. This study suggests that the use of engaging students with literacy strategies in a laboratory environment enriches student understanding of the lecture and possibly lends structure to student apprehensiveness towards the sciences. It is important to note that this study took place over only one semester, within one course, at one institution and the simple increase in instructor interaction during the lab section could play a factor in the results. 
According to Dominguez and McDonald (2009) Student writing with selfreflection can generate numerous benefits when incorporated to coincide with scientific inquiry activities. These reflections strengthen critical thinking skills, leading students to better understand the purpose of their classroom activities and how to reach proper conclusions efficiently. Each conclusion is built upon a scaffold they themselves have built by becoming an active participant, previously physically and now cognitively. This reflection provides the instructor with a clear assessment tool to better structure their lessons in order to address concepts students are struggling with or mitigate time which would otherwise would have been redundantly used working material already mastered. These reflection activities can be undertaken as individual endeavors or as group activities. When utilized within small groups, reflective writing can provide students the opportunity to share and garner peer feedback in a nonjudgmental environment. To better channel student thinking, greatly refined guiding questions can be implemented. By adapting this format of self-examination to science activities student communication skills are improved, core ideas are given a solid foundation, and problem solving is bolstered all within a clearly defined greater context.

Christensen and McCrindle (1995) used learning journals to examine how first-year university students enrolled in an introductory level biology course are affected by their understanding of what learning is, a specific method of cognition, and how to fully implement those methods in a metacognitive context. The 40 students were split into one experimental and one comparison group. Once per 
week for five weeks students in the experimental group were given explicit instructions on how to reflect upon course content and the process of learning. The comparison group was to write scientific reports over activities through the use of a supplied workbook, each requiring the same time and effort as the journals of the experimental group. The reports were reviewed each week to record learning and given corrective feedback when necessary. At the end of each session the journal entries were evaluated where positive reflection was acknowledged but inappropriate reflection was supplied with deeper probing questions. The journals were used to assess students' ability to recognize metacognitive strategies. Researchers broke down these strategies to ascertain each student's ability to organize conceptual knowledge, academic achievement, and cognitive strategy use. Cognitive strategies were split into three primary categories: rehearsal, organization, and elaboration.

Other methods of measurement included a learning strategy test, which required each student to read a passage and later recall the information on an exam. During the reading each student was allowed one blank sheet of paper in order to structure notes pertinent to learning the reading material. Student interviews were also taken to glean student values and impressions of learning as a concept and the final exam scores for gauging academic achievement. Not only did the experimental group outperform the comparison on the final exam, but also showed higher control in metacognitive ability on the learning strategy task. The comparison group relied more heavily on rehearsal versus the experimental group, which used more elaboration and organizational cognitive strategies. Rehearsal strategies are more 
reliant on memorization and defining known information as opposed to structuring and linking old information with new information as in the other two. During the interview process the experimental group also provided longer answers richer in detail. These findings provided evidence that reflection journals were more apt to yield students involved in analyzing and interpreting new information versus the group simply writing lab reports, who relied more on acquisition and regurgitation of facts. Displaying metacognitive ability and following through with cognitive strategies implies a strong likelihood of a continuous cyclical process occurring between the two (Christensen \& McCrindle 1995).

In responding to a lack of research for using journals as strategy identifiers, Gogger, Holzäpfel, Nückles, Renkle, and Schwonke (2012) introduced journal writing as a means to explore whether quality or quantity of cognitive or metacognitive strategies could be assessed in this way, or if specific combinations of the two were indicators of learning outcomes. This two-part study first focused on $2369^{\text {th }}$ grade German medium track high school math students over a 6-week period focusing on the lesson of probabilities. All students underwent a journal tutorial in order to understand the goals, methods, and strategies of journal writing, as well as given explicit prompts to nurture the cognitive and metacognitive aspects of writing. Students were grouped into four clusters based on their use of strategies: balanced users, purely surface users, cognitive and metacognitive users, and strategy avoiders. A pretest and posttest was used to measure content knowledge and a questionnaire of student goals and motivation was administered to ensure 
that strategy use and learning outcomes were not just reflections of individual student motivations. Based on the scoring of journal entries, quantitative use of cognitive strategies seemed the strongest indicator of positive learning outcomes, while the quality of entries were a slightly weaker indicator. The cognitive strategies of elaboration and organization, both of which are considered associated with deeper mental processing were especially strong indicators. Quantity and quality of the journal entrees were weak indicators of learning outcomes for the subject of mathematics.

The second part of that study utilized the same methodology but instead with $1449^{\text {th }}$ grade biology students split into eight classes over a 6-week period. The focus for this study was that of inheritance. In this case, quality of the strategies was mid-scale except for rehearsal, which relates to basic outlining of known material. Rehearsal was also used more frequently followed by organization. Within this posttest metacognitive quantity and quality were weak predictors of outcomes as opposed to that of cognitive strategies being significant predictors. Students that partook in both a combination of metacognitive and cognitive strategies produced the highest overall learning outcomes, and strategy avoiders the lowest. Between these groups, students favored different strategies between the subjects of math and biology. Assessing the learning strategies through journal entries was successful in predicting learning outcomes. Successful biology learners favored rehearsal cognitive techniques. This possibly reflects the importance of text selection for main ideas within biology and aligning related concepts. Further instructor scaffolding could be implemented as a means to overcome learning 
deficits through increased prompts, workable examples, or classroom peer review. One area of study to consider is how student motivation relates to use of learning strategies and how to overcome these obstacles (Gogger et al., 2012).

\section{Peer Focused Writing}

The proposed benefits from writing-to-learn activities are to encourage critical thinking skills and overall conceptual understanding of learned material. Multiple models have been constructed to explain the connections between different forms of writing and the influence of mental operations at work. Among these models certain similarities present themselves: the writing process generates learning, feedback for the written work and the need for improvement through a cyclical nature, and finally that writing-to-learn methods need an explicit goal as opposed to writing for its own sake in order to maximize learning yields (Gunel, Hand, \& McDermott, 2008). This concept of requiring a specified objective and outside feedback led the researchers to inquire whether writing for different and authentic audiences with an explanatory goal and whether writing-to-learn activities themselves impacted understanding of student learning and deeper understanding of conceptual knowledge in biology. A quasi-experimental design utilizing a pretest and posttest was implemented on four groups of students made up of twenty $9^{\text {th }}$ grade and ninety-eight $10^{\text {th }}$ grade biology students in a high school located in the Midwestern United States. The research was carried out in two phases. Phase one required all students in the four sections to participate in a writing-to-learn activity explaining how homeostasis was maintained by the 
nervous system. This rough draft was written with the understanding that the teacher would be the desired audience. This standard activity implemented between the pre and posttest served as a baseline for comparison. The second phase split each class into writing for different audiences on how the circulatory and respiratory systems are interconnected. Class number 1 wrote based to an audience of $3^{\text {rd }}$ and $4^{\text {th }}$ grade students, class number 2 wrote for their parents, class 3 for their $9^{\text {th }}$ and $10^{\text {th }}$ grade peers. Finally class number 4 wrote again with the instructor serving as the primary audience. As with the previous cycle pre and posttests were comprised of multiple choice, true or false, and 3 essay questions. Results from phase one illustrated that the quality of the writing produced by students served as a strong indicator of how they scored on the posttest. In phase two, class $1,3^{\text {rd }}$ and $4^{\text {th }}$ grade audience, outperformed the class 4 , teacher audience, on conceptual questions. Class 4 did not demonstrate better results on any of the data collected, yet had higher previous biology grades and understanding of circulatory and respiratory systems than class 1 . Because class 1 outperformed class 4 on the conceptual questions it is possibly indicative that the cognitive activity involved between writing for younger students versus teachers are not the same. Here the students serve as a possible authority figure and must translate material for themselves first then into a form easily comprehensible. Whereas writing for an instructor may rely more heavily on simply reflecting information back without clear understanding of the concepts.

Writing to learn strategies have been used within the science classroom in the hopes of achieving a higher level of understanding of the material. 
Unfortunately, traditional low-level assessment techniques, such as straightforward questions relying on the recall of information, may not properly reflect whether or not a student has achieved that high level comprehension through the activity. To measure this connection, researchers Hand, Prain, and Wallace subjected groups of students to a mixture of writing tasks along with normal science instruction and afterwards measured their performance on a unit test which included both low and high-level test questions (2002). Two studies were carried out over the span of two semesters among year 9 and 10 secondary science students in Victoria, Australia using the same instructor. The first study focused on genetics and required the treatment group to write a letter to the editor of a newspaper that elaborated on the positives and negatives of genetic filters in cloning. Here the comparison group were assigned extra end of chapter problems from their textbooks instead of participating in a letter writing assignment. The second study revolved around the subject of light reflection and refraction where the treatment group not only wrote a letter but also participated in five activities based around the science writing heuristic. This time the audience for the letters was to be year 10 students in the United States, and explain what was learned throughout the unit covering light reflection and refraction. The comparison group participated in the same number of lab activities outlined in their textbooks and end of chapter questions. After each unit for both studies the instructor's normal exam was given to the students for the respective topic. The exams included true or false, multiple choice, and short answer questions, as well as a single analogy question requiring higher order thinking developed by the research team. Study number one showed no statistical significance in test 
scores between the comparison and treatment groups. Among the fifteen students who finished the letter portion in study one, eleven displayed higher order thinking. Students participating in the second treatment group did demonstrate higher scores of statistical significance on the analogy question, but none over the lower order test questions. Here only seventeen students of the twenty-three finished the letter, but twelve of those students illustrated their understanding of the two or more higherlevel concepts. These twelve students were interviewed in order to identify each one's understanding of the writing-to-learn tasks. One point which stood out to the researchers was that the students felt the need to elaborate more when writing the letter to a peer as opposed to writing directed at the teacher. The researchers concluded that a combination of writing tasks did illustrate a benefit to student learning and their metacognitive processes, at least in regards to the subjects of light and genetics. Although there is a clear need for exams to be created so as to reflect this higher level of student thinking.

\section{K-W-L Strategy}

Although the use of K-W-L and journal writing has been touted to increase comprehension of studied material, Cantrell and Fusaro (2000) noted a lack of experimental data to support these theoretical claims. For this reason they carried out a comparative study to help determine if a difference in learning social studies content was present among $7^{\text {th }}$ grade students using either a K-W-L journal writing format or that of summary journal writing. The study included $897^{\text {th }}$ grade social studies students split among 4 classes, two taught in the morning and two taught in 
the afternoon, each taught by the same instructor. One morning and one afternoon class were instructed on how to use the K-W-L format for journal writing to take place during the assigned reading while the remaining morning and afternoon classes were instructed how to properly summarize the assigned materials by following chapter titles and section headings throughout the school year. Multiple choice pre and posttest were used to determine which group of students displayed greater learning. The findings indicated that each class utilizing the K-W-L journal writing displayed significantly higher scores on the posttest over the basic journal summary classes. Because K-W-L strategies requires students to engage in a prereading thought process in order to lay out their current knowledge over a topic and a post-reading thought process to connect the new material, whereas the summary writers were confined to a only a post-reading thought process, this could be a possible explanation for why the K-W-L students outperformed the summary students.

The researchers Siribunnam and Tayraukham (2009) compared different styles of instruction within the classroom in order to observe each style's potential differences in learning benefits. Here the instructional methods compared were the 7-E, KWL, and conventional instruction. The 7-E is an inquiry based method based around seven phases starting with an elicitation phase to motivate student learning and ending in the extension phase giving the students a way of bridging the newly learned information within a personal relatable context for their lives. KWL strategy grants the students a way in which to tackle read material by addressing what the 
students know, want to learn, and have learned. This study also added another aspect to the KWL method by adding a fourth step allowing the students to conclude and present the information so as to create a more refined informative map of the material. For this experiment 362 grade 5 students in Thailand were split into three groups, each tackling one of the three different learning strategies over a course of six weeks. Two multiple choice posttests were given after the unit, one testing analytical skills and the other content knowledge of acids and bases. Students' attitudes towards chemistry were also recorded after the unit using a rating scale built on twenty items each on a five-point scale. Results indicated that teaching methods did in fact have an impact on student learning and analytical thinking. Although the 7-E treatment group did outperform the KWL treatment group in each tests, both treatment groups still outperformed the conventional teaching method. Possible reasons for the 7-E group outperforming the KWL group may include the 7E method granting more opportunity for the student's to structure their own learning and explorative techniques as well as providing ample opportunities for peer interaction. It is important to note how the KWL strategy does focus on reading, cognitive, and metacognitive skills to greater extent over the conventional method.

The K-W-L method can be utilized across a wide range of age groups as a simple means to address inquiry-based learning goals. Typically used within a written a framework, this strategy's versatility was applied to the lab sections of a university level introductory physics course for non-majors (Manivannan and 
Schaefer 2009). The K-W-L method relies on three basic premises, the first being the K. Here the ideas of what student should or do know are addressed. Next the W for what students want to know and leading course discussion into critical thinking territory and further engaging the students. Finally the $\mathrm{L}$ step for what has been learned, where students can reconfigure that new knowledge with the old. Here the author researchers applied the K-W-L strategy to four lab sections as an experimental group for one semester and taught three lab sections as normal to serve as comparison groups. At the beginning of each lab the Experimental classes would be engaged in concept mapping, questions, and clarifying any misconceptions from lecture as a part of the K step. Next the W step was implemented to make predictions based around the lab activities. The L step then addressed what knowledge students had gathered from the data collected and how it built into existing knowledge. To measure it's effectiveness the topic of vectors was chosen and understanding measured through the Vector Additional diagnostic Test (VADT), which asks conceptual questions regarding adding and multiplying vectors as well as determining balancing forces. Compared to the control lab section, which followed a traditional laboratory experience without group discussion, the experimental group scored an equal or greater percentage of answers correctly overall and a greater percentage over those questions deemed to be more complicated. Observations from the researchers also indicated that the experimental groups were more engaged in the material, asked more questions concerning the material, and produced better lab reports. Whereas the comparison sections sometimes had difficulty in recognizing why the lab activity was being done 
and what knowledge was gained from it. From this study the K-W-L appears to be an effective tool for connecting lecture material and laboratory activities.

\section{Summary}

According to the literature, literacy strategies have been shown to increase student content knowledge when incorporated into the classroom. Students that use literacy strategies produce higher test scores and in turn illustrate higher semester grades over students not using literacy strategies. Literacy strategies used along side lecture and laboratory work is thought to keep students more engaged in the sciences (Harmon \& Pegg 2012).

The versatility of the K-W-L literacy strategy allows it to be used across multiple subjects and not just along with student readings. K-W-L's can be implemented so as to bridge the realm of lecture material to laboratory activities (Manivannan \& Shaefer 2009). Another reason the K-W-L format is being implemented in this research is because it offers a teacher and student a friendly interface. The user's attention can be directed towards specific areas of learning through the method's simple question scaffolding. These questions engage the learner to make connections as opposed to blind rote memory and summation (Cantrell \& Fusaro 2000). The K-W-L strategy inquires about the preconceptions of a topic then has the student later revisit the material after the activity or lesson. An approach like this puts the learner in the position to plan out their experience to the content beforehand (Cantrell \& Fusaro 2000). Here the students will not simply be reacting to the lessons being taught, but will be able to anticipate and reflect. 
Literacy strategies, such as the K-W-L, can be easily integrated into science journal writing. These student journals can produce valuable feedback to the instructors. In this study the learning journals will offer the researcher insight into how much depth students put into their journal entries, as well as the strategies they employed (Christensen \& McCrindle 1995). However it is important to note that different content areas may rely on a different combination of strategies to maximize learning (Gogger, et al 2012). Journal writing also gives the student a platform to take responsibility for their learning and utilize metacognitive strategies (Dominguez \& McDonald 2009). These self-reflective exercises tie into the research by creating a cyclical exposure to the content for the subjects. They are given the opportunity to write out their thoughts, personal connections, and how new material relates to past material. The journal format here is greatly desired as a simple learning tool that can be refined with guided questions to focus on the necessary content (Dominguez \& McDonald 2009).

Writing-to-learn strategies that are carried out through learning journals provide many benefits for the student. These strategies allow for the organization of skills and ideas while granting increased exposure to the material. Mental connections can be made between lab activities and lectures (Harmon \& Pegg 2012), which coincides with Dominguez and McDonald's notion that writing activities bridge interactive modes of learning to a post cognitive place for self-reflection (2009). An important element to insert is conveying a clear, concise goal for the activity and considering who the student's audience is for the writing. To prevent the simple regurgitating of information back to the teacher authority figure, this 
research asks the subjects to write to peers that are unfamiliar with the material (Gunel, Hand, \& McDermott 2009), which forces the writers to elaborate and translate the material into a form that is easily understood (Hand, Prain and Wallace 2002). The idea is that students will personalize and own their learning through these types of interactions and allow them to display higher order thinking skills. What makes this research unique is that it has attempted to insert the K-W-L literacy strategy into science journal writing and by explicitly stating that journal entries be written for an audience of student peers. 


\section{Method}

\section{Overview}

This study attempted to discern to what extent reflective journal writing implementing K-W-L prompts increased high school students' understanding of biology content knowledge. Using a quasi-experimental design, two high school biology classes studied the same content units. For the treatment unit the students used learning journals supplied with K-W-L prompts covering different sections of the first unit. These questions addressed what the students knew $(\mathrm{K})$ about the topic before the lesson, what information the students want (W) to know about the topic, and finally what the students learned (L) from the class session and still wanted to learn. The students were given explicit directions on how the journal entries should be written and to consider how each topic relates to any information from the previous lessons or personal knowledge so as to promote a cyclic approach to learning. During the comparison unit, the same students also used journals, but they were only asked to write about that information that was covered in class. During the treatment and comparison units the students were directed to write their entries as if relating information to a peer or individual unfamiliar with the material. Each unit of biology used for the treatment and comparison units dealt with the subject of evolution. Each unit was outlined and planned by the biology department of the study school and the researcher. This insured that the content of both the units used for the treatment and comparison were of equal difficulty for the students. The independent variable implemented for this study was the student's use of the K-W-L journals, while the dependent variable was the learning gains in 
biological knowledge as measured by a pre and posttest given to each group. The pretests were used to determine whether or not the units are equivalent. Pre and posttest gains of the two units were compared using a t-test. This determined whether or not the K-W-L strategy provided an advantage. Post trial student interviews of four students in the study were conducted in order to gather qualitative information. This qualitative data recorded student impressions of the strategy and whether they plan to use the strategy in the future. These students were also be asked if they noticed themselves using parts of the strategy during the open ended journal writing activity if any was observed by the researcher. This set of questions will be conducted to ascertain whether the K-W-L strategy was implemented for the second set of journal entries when no direct format was required.

Table 1: Experimental design

\begin{tabular}{|c|c|c|c|c|c|}
\hline & \multicolumn{3}{|c|}{ Treatment Unit } & \multicolumn{2}{|c|}{ Comparison Unit } \\
\hline $\mathrm{Na}$ & $\mathrm{OT}_{\mathrm{T}}$ & $\mathrm{X}$ & От & От & $\mathrm{O}_{\mathrm{T}, \mathrm{I}}$ \\
\hline $\mathrm{Nb}$ & $\mathrm{OT}_{\mathrm{T}}$ & $\mathrm{X}$ & От & От & От, I \\
\hline
\end{tabular}

$\begin{aligned} \text { Key: } \mathrm{Na}=\text { non-randomized Class } \mathrm{A} & \mathrm{O}_{\mathrm{T}}=\text { pre- and post-treatment test } \\ \mathrm{Nb}=\text { non-randomized Class } \mathrm{B} & \mathrm{O}_{\mathrm{I}}=\text { interviews } \\ \mathrm{X}=\text { treatment; } \mathrm{K}-\mathrm{W}-\mathrm{L} \text { Journals } & \end{aligned}$




\section{Participants}

\section{Context}

This study will observe a set of public high school biology classes within the Portland, Oregon school district. Each class will cover the same two units of biology, similar in difficulty and taught by the same instructor.

\section{Number of groups}

Two public high school biology classes will be observed and tested for this study. Members of the classes were within a 3-year age range and at the $10^{\text {th }}, 11^{\text {th }}$, or $12^{\text {th }}$ grade level. The gender ratio for the student participants was 17 females: 8 males.

\section{Number of participants}

The class designated as Group A had 10 students participate in this study. Group B had 15 students participate in this study. Because these classes will collectively be used for the treatment and comparison units, this study had a total of 25 participants.

\section{Demographics}

Participating class demographics are broken down in Table 2 as group A and group B. 
Table 2: Class demographics

\begin{tabular}{|l|l|l|l|l|l|}
\hline Group & \multicolumn{2}{|c|}{ Gender } & \multicolumn{2}{c|}{ Grade } & \# of students \\
\hline & Female & Male & 10 th & 12th & \\
\hline A & 6 & 4 & 10 & & 10 \\
\hline B & 11 & 4 & 14 & 1 & 15 \\
\hline Total & 17 & 8 & & & 25 \\
\hline
\end{tabular}

\section{How selected}

The classes participating in the study were selected because both were studying the same level of biology, within the same school, and taught by the same instructor.

\section{How assigned to groups}

The students were non-randomly assigned to one of two classes to participate since the researcher has no control over class enrollment.

\section{Procedure}

Student participants of two high school biology classes, taught by the same instructor, within the Portland, Oregon school system were each subjected to an experimental treatment during their first evolution unit. For their second evolution unit the student participants were not given the treatment. The first iteration will begin with both classes taking a pretest over concepts of evolution they have not previously covered. The instructor and the researcher wrote both this pretest and the posttest. Each included the same questions or same type of questions. 
The purpose of the pretest was to establish a baseline for student knowledge about the content area for later comparison. The pretest will also illustrate that each class is equal in their content knowledge and performance to reinforce the validity of comparing the classes' learning gains over the course of the study.

Each class was given learning journals. During the first unit the journals contained K-W-L question prompts built around the content to be taught. Student participants were instructed how to properly use these K-W-L journals and delivered a brief demonstration. The first portion involved only the K and W steps about a topic. This allows the student to relate what they currently know about the upcoming topic and what they may want to know. The students were given time at the start of class to answer the K and W questions in their journals. After the lecture or class activity the students can reflect back on what they have learned, the L step. Students were also given class time at the beginning of the next class period to answer the L step prompt of the K-W-L. Each student can go onto the K and W steps for the next area of the unit and how it may relate to what was previously covered. These journals with K-W-L scaffolding will encourage students to participate in a cyclical learning process, allowing them an explicit means to connect previous knowledge with new knowledge.

Learning journals used during the second evolution unit did not contain the K-W-L outlining questions for each entry. Instead the students were given the simple instructions to write about what they covered in class and what they learned. These students were given no restrictions on how to structure or formulate these journal entries. Each group was expected to write two to three journal entries per 
week. These journals were collected by the instructor at the end of each week and graded for completion. This was done in order to ensure consistent student participation.

The students were also clearly instructed that their journal entries should be written as if relating information to another student who is similar in age and not familiar with the material. The inclusion of a defined audience for all student entrees can reinforce that students are not merely parroting scientific jargon in the hopes the instructor will understand it, but cause them to explain and elaborate information as if to a third party. Student participants become the voice of authority and instruct other students (Gunel 2009).

For the comparison portion of the study the same two classes were subjected to a pretest written by the instructor and researcher. As in before, this test covered additional information from their upcoming unit, unfamiliar to the students. This second unit was also based on the evolution, but different components. Learning journals were dispersed to each group of students. Student participants were now given the simple instruction to write entries about what they have learned and covered in the previous class. Here the students were not restricted on how to structure or formulate their entries. This allowed the students to implement the simple K-W-L format if they chose. Once again, each week journals were graded for completion with students' peers serving as a potential journal audience.

Once each unit was completed, all students were required to take a posttest written by the instructor and the researcher. These exams were as equally challenging as their corresponding pretest. Group scores were compared using a t- 
test to establish whether students' scores when using journals with K-W-L scaffolding illustrated any advantage over the students' were no K-W-L prompts were provided. Posttest student interviews were conducted on students randomly selected. These interviews were used to gather qualitative information about the KW-L strategy when used in journal writing. Interview questions will focus on student impressions, motivations to use the strategy, and their likelihood to continue using the strategy independently.

Post unit interviews were conducted on randomly selected students. These questions focused on student impressions, motivations to use the strategy, and likelihood to continue using the strategy on their own. Students interviewed whose entries followed the K-W-L strategy, or similar formats, when not prompted were asked probing questions about its use and whether they noticed. Questions here focused on why the student's chose to follow the format, difficulty of following K-WL strategy without prompts, and whether they would continue to use the strategy in the future.

\section{Treatment}

\section{Experimental treatment}

In this study the student participants were supplied journals with $\mathrm{K}-\mathrm{W}-\mathrm{L}$ question prompts during the treatment unit. These questions established what the students knew previously, want to know, and learned from the class activity or 
lecture. The students were given time in class to write these entries at the beginning of the class period.

\section{Control treatment}

The control group also received journals but was not given explicit K-W-L prompts. Instead the control group was given the simple direction of writing what they learned from the previous class activity or lecture. As in the experimental group, the students were given time in class to write these journals entries. During this comparison unit phase of the study the students were informed they may structure their journals in any way they believe will be beneficial to them.

\section{Instruments}

\section{Pre and Posttest}

The pre and posttests implemented for this study will be ones developed by the instructor and researcher for each observed unit. The scores were then compared using a t-test to establish if any advantage was observed for when the students used the K-W-L question prompted journals.

\section{Student Interviews}

Students randomly selected were subjected to semi-structured interviews. Through these interviews student impressions, understanding of the K-W-L journal writing exercise, and their willingness to partake in the method later were 
established. The following questions were asked by the interviewing researcher and followed up for clarification or elaboration if need be:

1) Do you feel like the KWL strategy helped you learn and recall the material better? Why/why not?

2) Was being provided with question prompts better than simply being asked to free write about the subject? Why/ why not?

3) Would you ever think about using the KWL strategy on your own? Are you likely to use it in the future? Why/ why not?

4) Is there anything else you would like to add about using this strategy?

Students that were observed to implement the K-W-L format or parts of it in their writing without the prompts will be asked specifics questions about their journal entry.

5) You were observed using the K-W-L format in your journal writing although it was no longer required, why was that?

\section{K-W-L Student Journals}

The journals distributed to students during their treatment phases contained $\mathrm{K}-\mathrm{W}$-L question prompts relating to specific topics within the unit to be covered. These questions began by asking what the student knows (K) about the topic and how it might relate back to material covered previously. The next portion granted 
the student the opportunity to elaborate on what they want (W) to know more about the topic or ask further clarifying questions. After the material was covered in class the student can move onto writing about what was learned (L) and possibly answer any of those presented questions or concerns. The quality of these entries was scored using a rubric developed by the researcher. This quality assessment helped further establish whether the depth and effort the student puts into the journal writing relates to the observed learning gains as opposed to it simply being the act of writing. Checking the caliber of given entries also provided the opportunity to check for strategy avoiders and whether the method was being properly followed and understood.

\section{Instrument reliability/validity}

Because this is a quasi-experimental design, a pretest was administered to establish how comparable the two units of study are. Having this information allows the researcher to assuage any worries about the presence of a selection bias between the treatment and comparison unit. Both parts of the study, the treatment and comparison, had the students participating in writing activities with the material. This way any results gathered from the study were not simply attributed to the extra work with the content or from engaging in a writing activity during the treatment unit. A t-test will be used to determine if any statistical similarities or differences in academic achievement are present between the pre and posttests

The pre-post test used in this study was the test usually used by the instructor as a summative assessment. Consequently it will have face validity, since 
it was the instrument typically used to measure student success and assessed the same learning targets as agreed upon by the research site's biology department. In this study parts of the test will be used as a pre-test as well. Reliability need not be determined if the test is multiple choice. In the case of constructed response items, a rubric will be developed, and two people (the instructor and researcher) will score a sample of ten student tests and compare the results to determine the percent agreement.

The rubric for the K-W-L journal developed by the author was evaluated for validity by showing it to three expert educators, including the course instructor, and revised accordingly. To insure the writing rubric used for this research had interrater reliability the researcher and another teaching professional scored twelve student journal entries. Table 3 presents these scores alongside their corresponding journal entry. Here the raw data shows consistency, but the last column of Table 7 goes on to illustrate the percent agreement between each score for the two observers. The total percent agreement for this particular rubric resulted in an $83.3 \%$ 
Table 3: Inter-rater Percent Agreement

\begin{tabular}{|l|l|l|r|}
\hline $\begin{array}{l}\text { Student Writing } \\
\text { Sample }\end{array}$ & $\begin{array}{l}\text { Grader \#1 Total } \\
\text { Score* }\end{array}$ & $\begin{array}{l}\text { Grader \#2 Total } \\
\text { Score* }\end{array}$ & Percent Agreement \\
\hline 1 & 3 & 3 & 100 \\
\hline 2 & 11 & 10 & 0 \\
\hline 3 & 9 & 9 & 100 \\
\hline 4 & 3 & 3 & 100 \\
\hline 5 & 3 & 3 & 100 \\
\hline 6 & 0 & 0 & 100 \\
\hline 7 & 3 & 4 & 0 \\
\hline 8 & 0 & 0 & 100 \\
\hline 9 & 4 & 4 & 100 \\
\hline 10 & 7 & 7 & 100 \\
\hline 11 & 6 & 6 & 100 \\
\hline 12 & 0 & 0 & 100 \\
\hline \multicolumn{2}{|l}{} \\
$*$ *Writing samples were scored out of a maximum of 12 points possible.
\end{tabular}

This positive measurement consistency was also seen when attempting to establish intra-rater reliability. Here the researcher scored a different set of twelve writing samples at four different times. The scores for each round and their corresponding entry are presented in Table 4. This data displays very minimal differences in student entry scores. 
Table 4: Intra-rater reliability scores

\begin{tabular}{|l|c|c|c|c|}
\hline $\begin{array}{l}\text { Student } \\
\text { Writing } \\
\text { Sample }\end{array}$ & Round 1 score & Round 2 Score & Round 3 Score & Round 4 score \\
\hline 1 & 11 & 11 & 11 & 11 \\
\hline 2 & 9 & 9 & 9 & 9 \\
\hline 3 & 8 & 8 & 8 & 8 \\
\hline 4 & 9 & 10 & 10 & 10 \\
\hline 5 & 7 & 7 & 8 & 8 \\
\hline 6 & 7 & 8 & 8 & 8 \\
\hline 7 & 10 & 10 & 10 & 10 \\
\hline 8 & 9 & 9 & 9 & 9 \\
\hline 9 & 9 & 9 & 9 & 9 \\
\hline 10 & 10 & 10 & 10 & 10 \\
\hline 11 & 11 & 11 & 11 & 11 \\
\hline 12 & 11 & 11 & 11 & 11 \\
\hline \multicolumn{5}{|l}{} \\
*Writing samples were scored out of a maximum of 12 points possible. & \\
\hline
\end{tabular}




\section{Results}

The results are broken down into 6 parts: 1) previous student content knowledge, 2) student learning gains, 3) relationship of K-W-L to treatment unit scores, 4) relationship of free writing to comparison unit scores, 5) student writing scores, and 6) student interview responses. Parts 1 and 2 will be presented with a table outlining the number of participants, mean, standard deviation, p-score, and confidence interval. The following portions 3 and 4 will present the regression equation to determine if a relationship exists between the test scores and the respective type of student writing. Section 5 will elaborate on the scoring rubric used to score student writing samples. Part 6 will present each question given in the student interviews followed by an overview of student responses. Although all pre and posttests were out of a total score of 50 points, total percent scores were used for data analysis in order to make it easier to compare to K-W-L and free writing student scores.

\section{Previous Student Content Knowledge}

The treatment and comparison units needed to be deemed equal in order to make any claim that the K-W-L treatment could influence students' content knowledge. To establish this equivalence of groups the students' treatment pretest scores and comparison pretest scores were compared using a Two-Sample t-Test. According to this t-Test no statistically significant difference was observed between the pretests of the treatment and comparisons units (see Table 5 and Figure 1). A pvalue of 0.263 illustrates that the confidence level of this equivalence is at 95\%. 
Table 5: Comparison of Pretest scores of Treatment and Comparison units for all participants

\begin{tabular}{|l|c|c|c|c|c|}
\hline $\begin{array}{l}\text { Pre- } \\
\text { posttest }\end{array}$ & $\mathrm{n}$ & $\mathrm{M}$ & $\mathrm{SD}$ & $\mathrm{p}$ & $95 \% \mathrm{CI}$ \\
\cline { 1 - 4 } Treatment & 25 & 7.76 & 6.39 & $0.263^{*}$ & $-1.49,5.33$ \\
\cline { 1 - 4 } Comparison & 25 & 5.84 & 5.57 & & \\
\hline
\end{tabular}

Note: This analysis was done using a Two-Sample t-Test. CI = confidence interval. A maximum of 50 points were possible on the pretest.

${ }^{*}$ p $>.05$ indicates there is no statistical difference in learning gains between units at a $95 \%$ confidence level.

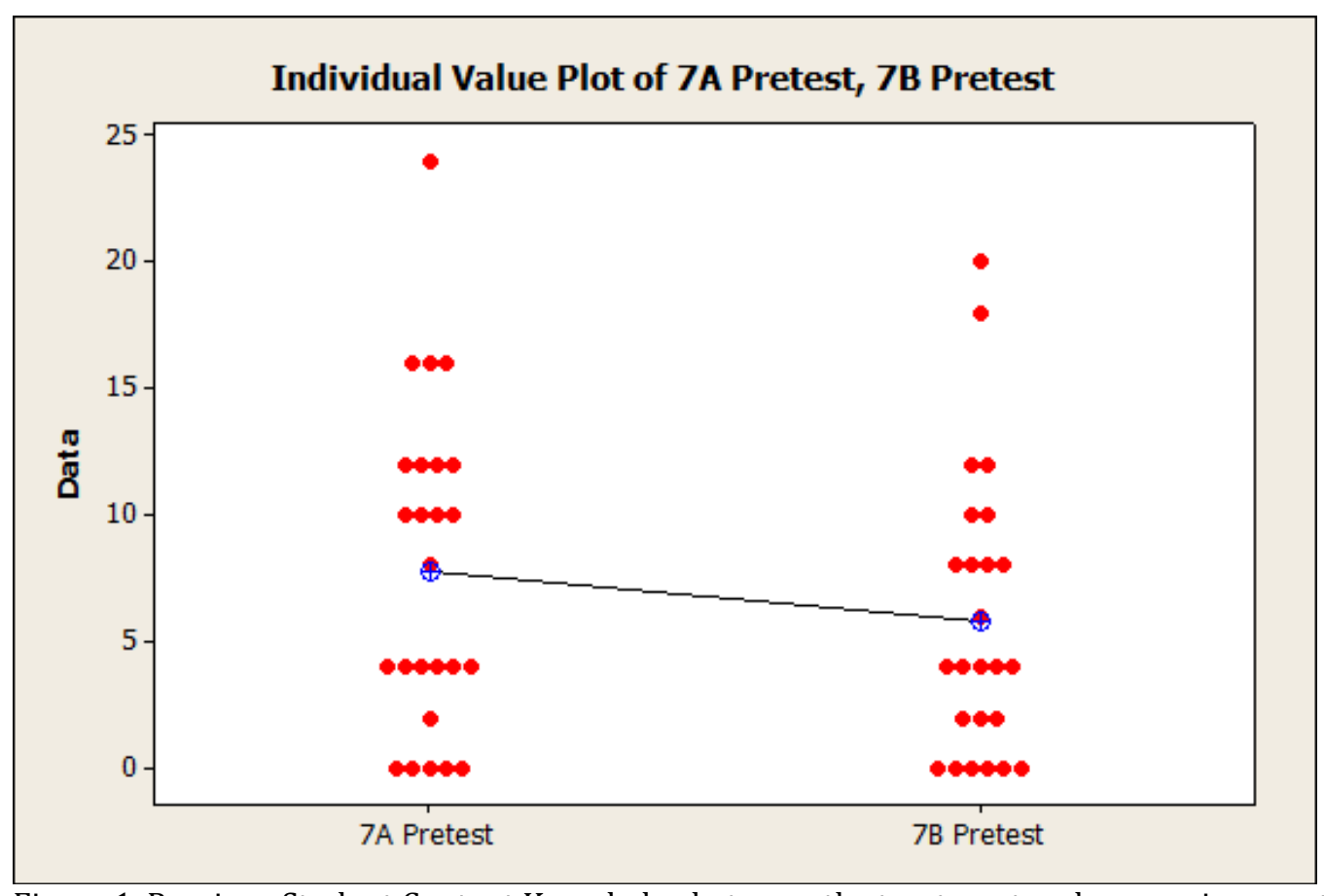

Figure 1. Previous Student Content Knowledge between the treatment and comparison pretest scores for all participants. The line shows the decrease in the mean score from the treatment to the comparison unit. $(\mathrm{p}=0.263)$.

This means that before each unit the students had similar levels of previous knowledge of the unit they were about to study when using the K-W-L strategy and when not using the strategy. Because of this the two units focusing on different aspects of evolution were acceptable for comparison. 
Figure 1 shows the student scores from the treatment and comparison pretests with a line connecting their mean values of 7.76 and 5.84, respectively. Both pretests had a low score of 0 , a high of 24 on the treatment pretest, and a high of 20 .

\section{Student Learning Gains}

In order to answer the question of whether students' biology content knowledge would be higher after using the K-W-L strategy, their learning gains from pre to posttest when using the strategy and when not using the strategy were compared. As was previously used, a Two-Sample t-Test showed that there was no statistical difference between the learning gains of students when they were and were not using the K-W-L strategy (see Table 6 and Figure 2).

Table 6: Comparison of learning gains on Pre and Posttest scores of Treatment and Comparison units for all participants

\begin{tabular}{|l|c|c|c|c|c|}
\hline $\begin{array}{l}\text { Pre- } \\
\text { posttest }\end{array}$ & $\mathrm{n}$ & $\mathrm{M}$ & $\mathrm{SD}$ & $\mathrm{p}$ & $95 \%$ CI \\
\hline Treatment & 25 & 70.2 & 19.8 & $0.092^{*}$ & $-2.01,25.85$ \\
\hline Comparison & 25 & 58.3 & 28.3 & & \\
\hline
\end{tabular}




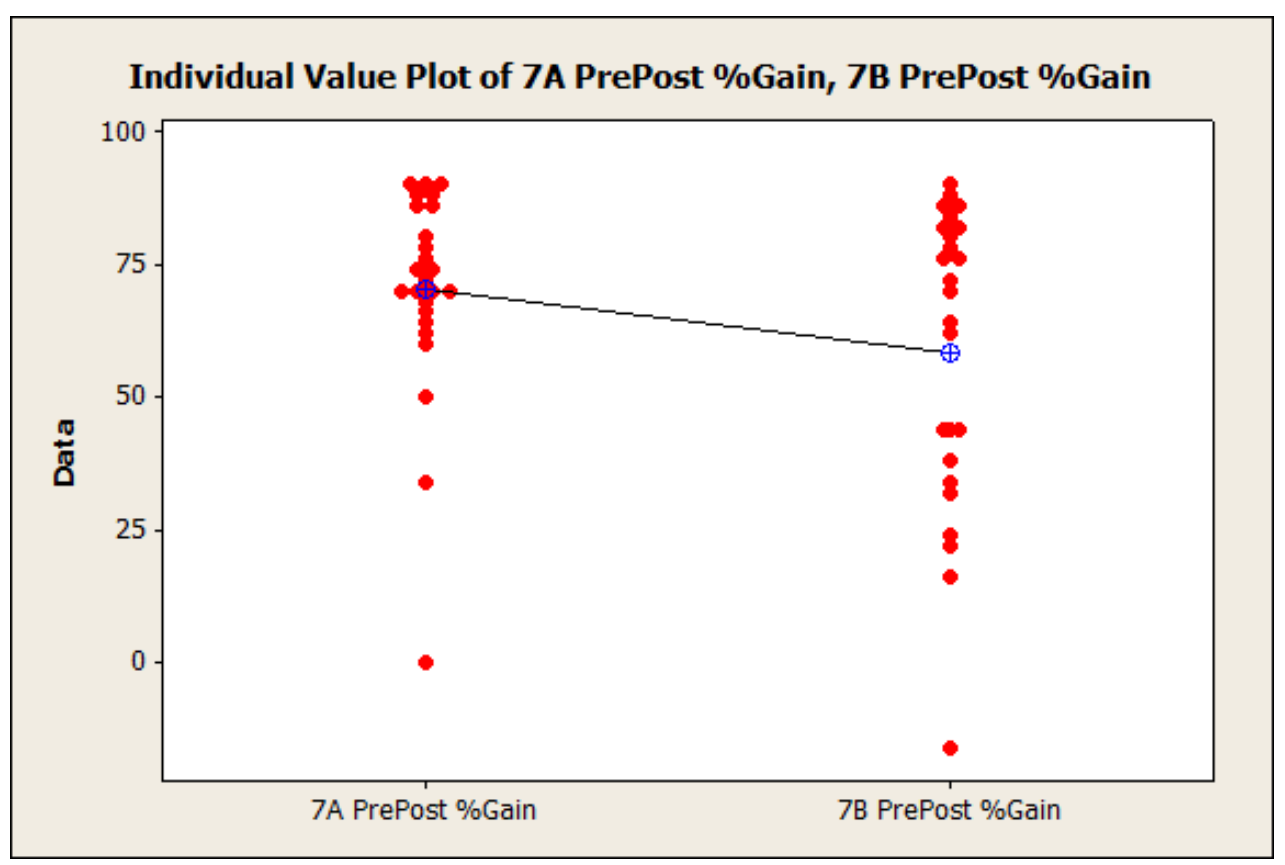

Figure 2. Student Learning Gains between the treatment and comparison pre and posttest scores for all participants. The line shows the decrease in the mean score from the treatment to the comparison unit. $(\mathrm{p}=0.092)$.

The line in Figure 2 shows a decrease in the mean scores of learning gains, a drop from 70.2 to 58.3. Although a p-value of 0.092 illustrates no statistical significance at a $95 \%$ confidence level, the standard deviation for the comparison unit was 28.3 versus the treatment's 19.8. Meaning that the student's learning gains were spread out further away from the average in the comparison unit than in the treatment unit.

The highest score on the treatment pretest was 48 with a low of 0 . Treatment posttest score resulted in a high of 98 with a low of 0 and mean score of 85.76. During the comparison unit the pretest was recorded to have a low score of 0 and a high of 40. The posttest for the comparison unit yielded a low of 0 and a high of 100 . Mean scores for the comparison unit's pretest was 11.68 and 70 for the posttest. Pre and posttest questions were comprised of fill in the blank and short answer. 


\section{Relationship of K-W-L to Treatment Unit Scores}

Although no statistical significance was found in the student scores when partaking in the K-W-L intervention or not, potential correlations between the two were investigated. Here student posttest percent scores were compared to K-W-L total percent scores, K-W-L Quality percent scores, and K-W-L Quantity percent scores in order to establish if any correlation exists between them. Regression analysis was used to determine the relationship among these variables. As seen in Table 7, only the K-W-L Total percent score was found to correlate to student posttest scores. Unlike the individual parts scored for Quality and Quantity, only the collective K-W-Ls produced a p-value less than 0.05 ( $\mathrm{p}$-value $=0.019$ ).

Table 7: Regression analysis of treatment unit scores

\begin{tabular}{|c|c|c|c|}
\hline $\begin{array}{l}\text { Regression } \\
\text { analysis of } \\
\text { treatment } \\
\text { posttest } \\
\text { compared to: }\end{array}$ & Regression equation & $\mathrm{p}$ & $\begin{array}{l}\text { Correlation } \\
\text { (yes/no) }\end{array}$ \\
\hline $\begin{array}{l}\text { K-W-L Total } \\
\text { percent score }\end{array}$ & $\begin{array}{l}\text { Treatment posttest score }=60.3+0.447 \\
\text { K-W-L Total }\end{array}$ & $0.019 *$ & Yes \\
\hline $\begin{array}{l}\text { K-W-L Quality } \\
\text { percent score }\end{array}$ & \multirow{2}{*}{$\begin{array}{l}\text { Treatment posttest score }=59.4+0.305 \\
\text { K-W-L Quality score }+0.148 \mathrm{~K}-\mathrm{W}-\mathrm{L} \\
\text { Quantity score }\end{array}$} & $0.301^{* *}$ & No \\
\hline $\begin{array}{l}\text { K-W-L Quantity } \\
\text { percent score }\end{array}$ & & $0.598^{* *}$ & No \\
\hline \multicolumn{4}{|c|}{$\begin{array}{l}\text { Note: } \mathrm{K}-\mathrm{W} \text {-L scores were out of a maximum of } 15 \text { points, but percent scores were used when } \\
\text { comparing them to student test scores. }\end{array}$} \\
\hline \multicolumn{4}{|c|}{$\begin{array}{l}* \text { p }<.05 \text { indicates there is a correlation between the } \mathrm{K}-\mathrm{W} \text { - } \mathrm{L} \text { total score and the Treatment posttest } \\
\text { scores at a } 95 \% \text { confidence level. }\end{array}$} \\
\hline \multicolumn{4}{|c|}{$\begin{array}{l}* * \text { p }>.05 \text { indicates there is no correlation in K-W-L Quality score or K-W-L Quantity score to the } \\
\text { treatment posttest scores at a } 95 \% \text { confidence level. }\end{array}$} \\
\hline
\end{tabular}




\section{Relationship of Free Writing to Comparison Unit Scores}

To determine if the act of any writing intervention would be correlated to students' posttest scores, the regression analysis was repeated for the comparison unit. Here the comparison posttest percent scores were compared to the free writing total, quality, and quantity percent scores. No correlation was observed between these scores, as summarized in Table 8 .

Table 8: Regression analysis of comparison unit

\begin{tabular}{|c|c|c|c|}
\hline $\begin{array}{l}\text { Regression } \\
\text { analysis of } \\
\text { comparison } \\
\text { posttest } \\
\text { compared to: }\end{array}$ & Regression equation & $\mathrm{p}$ & $\begin{array}{c}\text { Correlation } \\
\text { (yes/no) }\end{array}$ \\
\hline $\begin{array}{l}\text { Free Writing } \\
\text { Total percent } \\
\text { score }\end{array}$ & $\begin{array}{l}\text { Comparison posttest score }=56.6+ \\
0.298 \text { Free Writing Total }\end{array}$ & $0.162^{*}$ & No \\
\hline $\begin{array}{l}\text { Free Writing } \\
\text { Quality percent } \\
\text { score }\end{array}$ & \multirow[t]{2}{*}{$\begin{array}{l}\text { Comparison posttest score }=57.1+ \\
0.061 \text { Free Writing Quality score }+ \\
0.525 \text { Free Writing Quantity score }\end{array}$} & $0.875^{*}$ & No \\
\hline $\begin{array}{l}\text { Free Writing } \\
\text { Quantity percent } \\
\text { score }\end{array}$ & & $0.387^{*}$ & No \\
\hline \multicolumn{4}{|c|}{$\begin{array}{l}\text { Note: Free Writing scores were out of a maximum of } 9 \text { points, but percent scores were used when } \\
\text { comparing them to student test scores. }\end{array}$} \\
\hline
\end{tabular}

\section{Student Writing Scores}

The K-W-L and free writing journal entries were scored using a writing rubric created by the researcher (see appendix A). This rubric was revised after receiving input from other educators and the research advisor. The rubric was split into two sections looking at different aspects of the student writing. These aspects 
were the quality of the writing and the quantity of writing the student engaged in. The first section of the quality score sought if students attempted to identify any previous knowledge they had about the topic. This rubric goes on to score students' use of rehearsal cognitive processes by their ability to identify and describe science content. The final piece looks to see if students presented any questions or personal thoughts on the subject. Because students were not explicitly asked about previous knowledge or to ask questions during the comparison's free writing entries, unlike in the treatment's K-W-L strategy, these portions of the rubric were not used when scoring the free writing entries. Using these parts of the rubric would unfairly skew the qualitative results between the types of entries. When comparing these entries the percent score was used as opposed to their raw score. Quantity scores were based merely on the sum of the writing itself, which was done by counting how many sentences were observed in each entry.

The rubric evaluated student journal entries into these categories based on different levels of skill. These varying skill levels were titled section not attempted, does not meet, meets requirements, and exceeds. These sections quantified by receiving numeric scores ranging from 0 to 3 . These numeric scores were used to make comparisons to student posttest scores.

It is important to note that no students in this study provided additional questions in the L step of the K-W-L journal entries. The L step of the K-W-L asked the students to identify what they had learned and what additional questions or unanswered questions they have about the topic. All student participants avoided 
this part of the organizer. Because of this students received no additional points on the scoring rubric towards asking further questions about the content.

A selection of student responses with different skill levels will be presented here, except for entries receiving a score of zero where no attempt was made. The following excerpts demonstrate students with a "does not meet" skill level. These types of responses received a score of 1 . Typically these responses presented only one response or responses with sizeable mistakes in understanding.

- "We are some how related to monkeys."

- "I want to learn how evolution works."

Student entries receiving a score of 2 and deemed "meets requirements" will be presented next. These student responses may have accurately identified or described previous knowledge and science content, but made very slight mistakes or only presented two ideas per category.

- "How did Primates evolve into humans? What does artificial selection have to do with evolution?"

- "Evolution is change over time. Evolution happens by natural selection. Natural selection $=$ survival of the fittest"

- "I want to learn step by step how animals developed over time. For example is it because of mutations, environment, adaptation etc."

Entries attaining the "exceeds" skill level presented numerous examples of previous knowledge, asked questions, or explained and identified three or more 
science concepts. Although an entry may score very highly by identifying numerous points of content, if the student failed to explain or elaborate on those concepts their score for describing would be low.

- "Primates and humans have a similar body structure. Both have opposable thumbs. We also have similar genetics. Different Species living in the same Environment might have adapted the same appearance."

- "There are 3 types of structural evidence: Homologous: similar structures but different purposes. Analogous: Different structure but same purpose. Vestigial: Parts that no longer function. Geographic distribution of North America - animals in different countries similar body structures because of natural selection changes."

- "Evolution by natural selection. 7 main points of it - genetic variation, competition, offspring, survival of the fittest, descent with modification, common ancestor, adaptation. Why are these the 7 steps? Why only 7?"

- "I learned that modern primates evolved from common ancestors. Primates are monkies \& great apes. Humans are hominids. Theories of us evolving is standing up straight to see over grass \& etc."

\section{Student Interview Responses}

This section of the results will serve to highlight student response to each interview question. For more in depth recording of student responses please see the appendix B. Keep in mind these interviews were not audio recorded, but 
transcribed by the researcher. All quotations were repeated back to the student subjects in order to make sure each was being quoted accurately.

Question 1) Do you feel like the KWL strategy helped you learn and recall the material better? Why/why not?

Two of the four students interviewed, students A and D, had positive feelings towards the K-W-L strategy, each expressing how they "liked" the K-W-L. Both of these students expressed how the strategy helped remember class content later. Student A noted how "every [K-W-L] felt like a pretest for every lesson," and treated the strategy as a review. While student D remarked how the strategy aided him in asking questions. These questions made him go back through the class material later in order to identify what he did not know. Here student A and D are describing metacognitive aspects of the K-W-L strategy. These metacognitive strategies of identifying ones current knowledge and pursuing answers to unknowns were not identifiable when scoring the K-W-L student entries.

Of the students that were not fans of the strategy, students B and C, student C agreed that the "L step" and "repetition helped" when recalling information. She went on to express how she felt the $\mathrm{K}$ and $\mathrm{W}$ steps were a not helpful in recalling information. When asked to write questions she was unsure what to write. Student B stated that after completing the K-W-L organizer he never thought or looked at the strategy again. 
Question 2) Was being provided with question prompts better than simply being asked to free write about the subject? Why/ why not?

When comparing the K-W-L strategy to the more open ended free writing journal entries the students participated in while a part of the comparison unit, students A, B, and D all agreed that being provided guiding questions was better. Student A expressed that the guided questions and set up of the K-W-L was easier to follow and more organized. Student D expanded on this sentiment by explaining that the entries were "better with chart." This chart allowed him to outline what he learned before, ask questions, get help, and then repeat the process.

Student $\mathrm{C}$ was the only student to prefer the free writing journal entries. She felt the open-ended entries "helped more." According to her, these forced her to remember the key points for herself instead of just filling out the K-W-L chart.

Question 3) Would you ever think about using the KWL strategy on your own? Are you likely to use it in the future? Why/ why not?

Student responses here varied greatly. Student A stated that he had used the strategy before in a different class and would maybe continue to use it on his own. Student $\mathrm{C}$ had also used the strategy before in an algebra class, but she felt she would use the free writing process in the future and not the K-W-L. This feeling was shared by student B by stating he would probably never use it again.

Student D had never used the K-W-L strategy before participating in this study. However he went on to explain that since being exposed to the strategy he had been using a variation of it in his global studies and English class on his own. In 
the margins of his papers he would create a simple T-chart. In the right column he would record the information that he knew and then write questions he still had about the material in the left column. Later he would attempt to get these questions answered by the teacher. Here the researcher sketched what the student was describing and asked if this T-chart was accurate. Student D agreed, reiterating that he had not been using this method before being shown the K-W-L strategy.

Question 4) Is there anything else you would like to add about using this strategy? Only students A and D had additional thoughts on the K-W-L strategy. Student A felt the most important part of the organizer was the L step. This opinion would seem to align with student C's response to question 1 when stating that the $\mathrm{K}$ and $\mathrm{W}$ steps were the least beneficial to recalling information. Under that question student C agreed that the L step was the most important. Conversely, student D didn't "think you need the L step." This coincides with student D's use of his own devised graphic organizer based on the K-W-L. Here he would only use the K and W portions for his T-chart.

Question 5) You were observed using the K-W-L format in your journal writing although it was no longer required, why was that?

Of the students interviewed only one was observed using any portion of the $\mathrm{K}-\mathrm{W}$-L strategy during the comparison unit's free writing journal entries. This was student B. Student B's free writing journal entries would each begin with "I know" and then identify and explain concepts covered in class. This method of writing is the same one used in the K step of the K-W-L strategy, where the K column gives the 
student the opportunity to present any information they know about the topic or subject. When this was pointed out to student B he merely remarked that he had not realized he was beginning every entry that way. When pressed he expressed that he thought it was interesting but would not elaborate any further. 


\section{Discussion}

This research was conducted in an attempt to answer the question to what extent can the use of K-W-L prompts in science journal writing increase students' content knowledge? To answer this question the learning gains observed from the students' pre to posttest scores were compared when using the K-W-L strategy and when not using the strategy. No significant difference was observed between the treatment and comparison units according to a Two-Sample t-Test. Meaning that the use of the traditional K-W-L format provided the students with no significant benefit on posttest scores when compared to the alternative, open writing journal entries.

\section{Limitations}

To fully appreciate this study, certain limitations must be considered. This research was conducted within the confines of one classroom with student participants spread across two different class periods. Because the pool of potential student participants was small and non-randomized, so was the sample size $(\mathrm{n}=25)$. With such a limited sample size this research should be classified as a case study.

The researcher designed all the K-W-L graphic organizers and scoring rubric for student journal entries. Because of this these instruments have not been validated by any other studies. The researcher scored all pre and posttests, and student journal entries. The rubric used to score the student journal entries was subjected to tests of inter-rater and intra-rater reliability. But these tests were not extensive or in depth. This was because the main focus of this research was not to validate a scoring rubric. The rubric was just used to give a quantitative value to 
look for relationships between students' written work and test scores. The percent agreement for inter-rater reliability was only $83.3 \%$, high but not ideal. These must all be considered when viewing the findings of this study.

\section{Recommendations}

Although no significant difference was observed between the students' learning gains, the total scores of the $\mathrm{K}-\mathrm{W}$-L journal entries did correlate to their achievement on the posttest. However, the total free writing journal entry scores did not correlate to student achievement on the posttest. Meaning that how well students performed on $\mathrm{K}-\mathrm{W}$-L entries could potentially serve as a tool for formative assessment and a predictor of student success on summative assessments. Allowing teachers to target students who are experiencing difficulty before the end of unit exam by assessing their K-W-L entries. This coincides with the Dominguez \& McDonald's recommendation that writing exercises with self-reflective components can inform the direction of classroom instruction (2009).

To make sure this was not merely an issue of student motivation the quantity the journal entries for both the treatment and comparison units were compared using the same regression analysis against the student posttest scores. The thinking here was that motivated students would potentially write more than non-motivated students. This study in no way tried to measure student academic motivation, but this was the only data available that could potentially represent student motivation. The quantity scores for both the K-W-L and free writing journal entries demonstrated no correlation to students' posttest scores. This research's findings 
that quality and quantity of student journal entries are uncorrelated to student test scores align to previous studies. As mentioned in the literature, Gogger, Holzäpfel, Nückles, Renkle, and Schwonke found that quality and quantity too were weak indicators in student writing activities to student success (2012). Though that portion of their study was focused on the subject of mathematics instead of the subject of biology like this research. Additional research could lead to better identifying whether $\mathrm{K}-\mathrm{W}$-L scores serve as strong indicators of student success.

One issue that faced this study was the complete lack of students asking additional questions during the L step of the K-W-L. Most students simply participated in cognitive strategies such as rehearsal techniques, by listing learned science concepts and presenting very brief descriptions. Once again, this coincides with the Gogger et al. research. For the biology focus of that study the most commonly used and highest predictor of student success was the employment of rehearsal cognitive strategies (2012).

These commonly used rehearsal strategies answered the K-W-L question "What did you learn?" but not the second part of the L step, "Is there anything you still wanted to learn?" Students avoided putting forth additional questions about the material or going back and attempting to answer any of the lingering questions they had from the W step. One potential way to offset this avoidance in the future could be to further separate the K-W-L into a fourth column. This column would task the students with supplying additional questions about the material. An example of what this study is recommending can be seen in appendix C. 
The revised K-W-L graphic organizer still contains the same K and W steps as the ones used in this study. For this version of the strategy the L step has been split creating a four part graphic organizer. "What did you learn about" the topic is still aligned under the L step section. However, the part asking the users to provide additional questions has been moved to the last column. This column is given the title of "Q", as in Questions. The directions given to the user for this final section are to provide "What additional questions do you have about" the topic. It is this study's position that students may be more likely to provide these additional questions if given its own section of the organizer. The K-W-L organizer has been expanded in other studies. As mentioned in the literature, researchers Siribunnam and Tayraukham used a K-W-L in their study that contained a fourth step, though this step tasked students with concluding the subject matter and structuring it for class presentations (2009). Also, providing additional question scaffolding is recommended as a way to overcome learning deficiencies (Gogger et al., 2012). Granting this question its own column in the graphic organizer may potentially avoid students disregarding it.

Another aspect this research touched on was whether students would be inclined to use the K-W-L on his or her own because of its simplicity to integrate in to any subject or writing process. Based on free writing entries from the comparison unit and the student interviews conducted in this case study found that students could potentially use the K-W-L on their own without being supplied prompts. Free writing entries from the comparison unit started out by stating, "I know" before rehearsing the concepts from class. This was pointed out in the student interview B, 
though it only displays the use of the K step. One potential avenue for further investigation could task the students with further repeated use of the K-W-L strategy. This study only utilized three K-W-L journal entries. Having the students go through the process additional times and then slowly removing the question scaffolds may lead the students to self-implement and demonstrate more of the literacy strategy's key elements.

Student D's interview gave even more compelling evidence of future student use when he described using it on his own in other subjects. The student would write out what they knew and further questions they had for the teacher. This organized way of outlining his questions and the material aided him because he had "trouble understanding the teacher sometimes." It is important to mention that Student D was an English language learner. This variation on the K-W-L he was using let him clear up points of confusion with the teacher later. This could point to the K-W-L's potential future use with students learning English. 


\section{References}

Cantrell, R. J., \& Fusaro, J. A. (2000). Exploring the effectiveness of journal writing on learning social studies: A comparative study. Reading Psychology, 21, 1-11.

Christensen, C. A., \& McCrindle, A. R. (1995). The impact of learning journals on metacognitive and cognitive processes and learning performance. Learning and Instruction, 5, 167-185

Dominguez, L. \& McDonald, J. (2009). Reflective writing: Developing patterns for thinking about learning in science. The Science Teacher, 76.

Gogger, I. , Holzäpfel, L. , Nückles, M. , Renkle, A. , \& Schwonke, R. (2012). Learning strategies assessed by journal writing: Prediction of Learning outcomes by quantity, quality, and combinations of learning strategies. Journal of Educational Psychology, 104, 452-468.

Gunel, M., Hand, B., \& McDermott, M. A. (2008). Writing for different audiences: Effects on high-school students' conceptual understanding of biology. Learning and Instruction, 19, 354-367.

Hand, B., Prain, V., \& Wallace, C. (2002). Influences of writing tasks on students' answers to recall and higher-level test questions. Research in Science Education, 32, 19-34.

Harmon, L. L., \& Pegg, J. (2012). Literacy strategies build connections between introductory biology laboratories and lecture concepts. Journal of College Science Writing, 41, 92-98. 
Manivannan, M. K., \& Wrinkle, C. S. (2009). Application of the K-W-L teaching and learning method to an introductory physics course. Journal of College Science Teaching, 47-51.

Ogle, D. M. (1986). K-W-L: A teaching model that develops active reading of expository text. The Reading Teacher, 39, 564-570.

Siribunnam, R. , \& Sombat, T. (2009). Efects of 7-E, KWL, and conventional instruction on analytical thinking, learning achievement and attitudes toward chemistry learning. Journal of Social Sciences, 5, 279-282. 
Appendix A: Instruments

K-W-L Graphic Organizer

Topic: Theory of Evolution

\begin{tabular}{|c|c|c|}
\hline $\mathrm{K}$ & $\mathrm{W}$ & $\mathrm{L}$ \\
\hline $\begin{array}{l}\text { What do you know about } \\
\text { the theory of evolution? }\end{array}$ & $\begin{array}{l}\text { What do you want to learn } \\
\text { about evolution? }\end{array}$ & $\begin{array}{l}\text { What did you learn about } \\
\text { evolution? Is there } \\
\text { anything you still wanted } \\
\text { to learn? }\end{array}$ \\
\hline & & \\
\hline & & \\
\hline & & \\
\hline & & \\
\hline & & \\
\hline & & \\
\hline & & \\
\hline & & \\
\hline & & \\
\hline & & \\
\hline & & \\
\hline & & \\
\hline & & \\
\hline & & \\
\hline & & \\
\hline & & \\
\hline & & \\
\hline & & \\
\hline & & \\
\hline
\end{tabular}




\section{K-W-L Graphic Organizer}

Topic: Evidence for Evolution

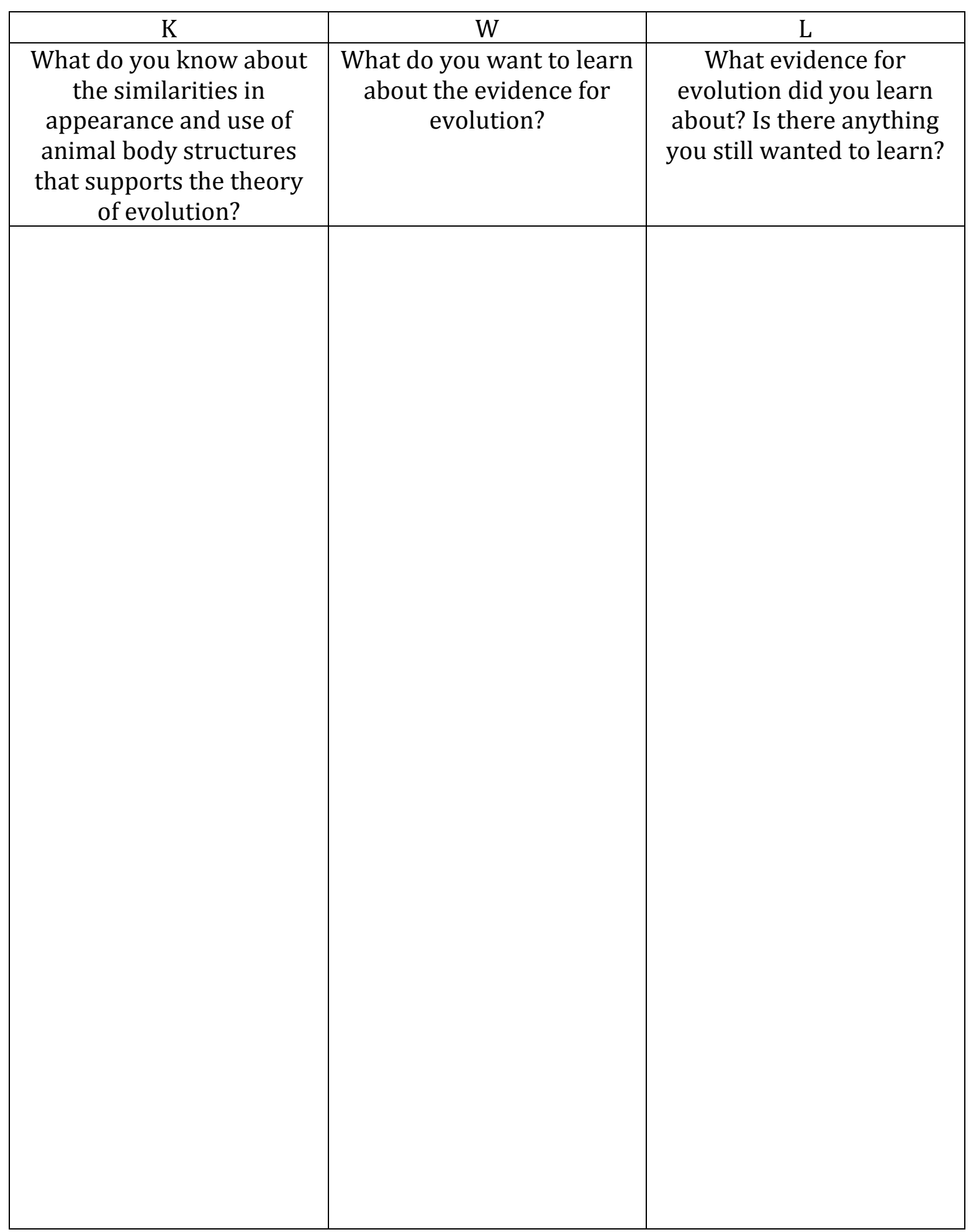




\section{K-W-L Graphic Organizer}

Topic: Human Evolution

\begin{tabular}{|c|c|c|}
\hline $\mathrm{K}$ & W & $\mathrm{L}$ \\
\hline $\begin{array}{l}\text { What do you know about } \\
\text { the evolution of humans? }\end{array}$ & $\begin{array}{c}\text { What do you want to learn } \\
\text { about the evolution of } \\
\text { humans? }\end{array}$ & $\begin{array}{l}\text { What have you learned } \\
\text { about human evolution? Is } \\
\text { there anything you still } \\
\text { wanted to learn? }\end{array}$ \\
\hline & & \\
\hline & & \\
\hline & & \\
\hline & & \\
\hline & & \\
\hline & & \\
\hline & & \\
\hline & & \\
\hline & & \\
\hline & & \\
\hline & & \\
\hline & & \\
\hline & & \\
\hline & & \\
\hline & & \\
\hline & & \\
\hline & & \\
\hline & & \\
\hline & & \\
\hline & & \\
\hline
\end{tabular}


Scoring rubric for Honors Biology science journal entries.

\begin{tabular}{|l|l|l|l|l|}
\hline \multicolumn{4}{|c|}{ Quality } \\
\hline & $\begin{array}{l}\text { 1-Section } \\
\text { not attempted }\end{array}$ & $\begin{array}{l}\text { 1- Does not } \\
\text { meet }\end{array}$ & $\begin{array}{l}\text { 2- Meets } \\
\text { requirements }\end{array}$ & 3 - Exceeds \\
\hline $\begin{array}{l}\text { Describe two } \\
\text { pieces of } \\
\text { previous } \\
\text { knowledge } \\
\text { about the } \\
\text { subject. }\end{array}$ & $\begin{array}{l}\text { Section left } \\
\text { blank }\end{array}$ & $\begin{array}{l}\text { Two pieces of } \\
\text { previous } \\
\text { knowledge } \\
\text { about the } \\
\text { subject is NOT } \\
\text { addressed in } \\
\text { the entry. }\end{array}$ & $\begin{array}{l}\text { Two pieces of } \\
\text { krevious } \\
\text { knowledge } \\
\text { about the } \\
\text { subject is } \\
\text { addressed in the } \\
\text { entry. }\end{array}$ & $\begin{array}{l}\text { Three or more } \\
\text { pieces of } \\
\text { previous } \\
\text { knowledge } \\
\text { about the } \\
\text { subject are } \\
\text { addressed in } \\
\text { the entry. }\end{array}$ \\
\hline $\begin{array}{l}\text { Identify (or } \\
\text { list) two or } \\
\text { more pieces of } \\
\text { science } \\
\text { content. }\end{array}$ & $\begin{array}{l}\text { Section left } \\
\text { blank }\end{array}$ & $\begin{array}{l}\text { Two pieces of } \\
\text { science } \\
\text { content is NOT } \\
\text { identified. }\end{array}$ & $\begin{array}{l}\text { Identifies two } \\
\text { pieces of science } \\
\text { content. }\end{array}$ & $\begin{array}{l}\text { Identifies } \\
\text { three or more } \\
\text { pieces of } \\
\text { relevant } \\
\text { science } \\
\text { content. }\end{array}$ \\
\hline $\begin{array}{l}\text { Describe } \\
\text { accurately two } \\
\text { or more pieces } \\
\text { of science } \\
\text { content. }\end{array}$ & $\begin{array}{l}\text { Section left } \\
\text { blank }\end{array}$ & $\begin{array}{l}\text { Describes } \\
\text { science } \\
\text { content with } \\
\text { sizeable } \\
\text { mistakes or } \\
\text { content } \\
\text { missing. }\end{array}$ & $\begin{array}{l}\text { Accurately } \\
\text { describes two } \\
\text { pieces of science } \\
\text { content. Or } \\
\text { makes minor } \\
\text { mistakes with } \\
\text { 3rd piece of } \\
\text { content. }\end{array}$ & $\begin{array}{l}\text { Accurately } \\
\text { describes } \\
\text { three or more } \\
\text { pieces of } \\
\text { science } \\
\text { content. }\end{array}$ \\
\hline $\begin{array}{l}\text { Identify two or } \\
\text { more } \\
\text { questions, } \\
\text { thoughts, or } \\
\text { personal } \\
\text { revelations } \\
\text { about the } \\
\text { subject. }\end{array}$ & $\begin{array}{l}\text { Section left } \\
\text { blank }\end{array}$ & $\begin{array}{l}\text { Two or more } \\
\text { questions, } \\
\text { thoughts, or } \\
\text { personal } \\
\text { revelations } \\
\text { about the } \\
\text { subject are } \\
\text { NOT } \\
\text { identified. }\end{array}$ & $\begin{array}{l}\text { Identifies two } \\
\text { questions, } \\
\text { thoughts, or } \\
\text { personal } \\
\text { revelations } \\
\text { about the } \\
\text { subject. }\end{array}$ & $\begin{array}{l}\text { Identifies } \\
\text { three or more } \\
\text { questions, } \\
\text { thoughts, or } \\
\text { personal } \\
\text { revelations } \\
\text { about the } \\
\text { subject. }\end{array}$ \\
\hline
\end{tabular}

\begin{tabular}{|l|l|l|l|l|}
\hline \multicolumn{5}{|c|}{ Quantity } \\
\hline & $\begin{array}{l}0-\text { Section not } \\
\text { attempted }\end{array}$ & $\begin{array}{l}\text { 1 - Does not } \\
\text { meet }\end{array}$ & $\begin{array}{l}\text { 2- Meets } \\
\text { requirements }\end{array}$ & - Exceeds \\
\hline $\begin{array}{l}\text { Total journal } \\
\text { entry is 5-6 } \\
\text { sentences. }\end{array}$ & $\begin{array}{l}\text { Section left } \\
\text { blank }\end{array}$ & $\begin{array}{l}\text { Total length of } \\
\text { journal entry } \\
\text { is less than 5 } \\
\text { sentences. }\end{array}$ & $\begin{array}{l}\text { Journal entry is } \\
\text { 5-6 sentences } \\
\text { long. }\end{array}$ & $\begin{array}{l}\text { Journal entry } \\
\text { is 7 or more } \\
\text { sentences } \\
\text { long. }\end{array}$ \\
\hline
\end{tabular}




\section{K-W-L Research Interview Questions}

Do you feel like the KWL strategy helped you learn and recall the material better? Why/why not?

Was being provided with question prompts better than simply being asked to free write about the subject? Why/ why not?

Would you ever think about using the KWL strategy on your own? Are you likely to use it in the future? Why/ why not?

Is there anything else you would like to add about using this strategy?

Specific questions about journal entry: 


\section{Appendix B: Student Work Samples and Responses}

\section{K-W-L Journal Entries}

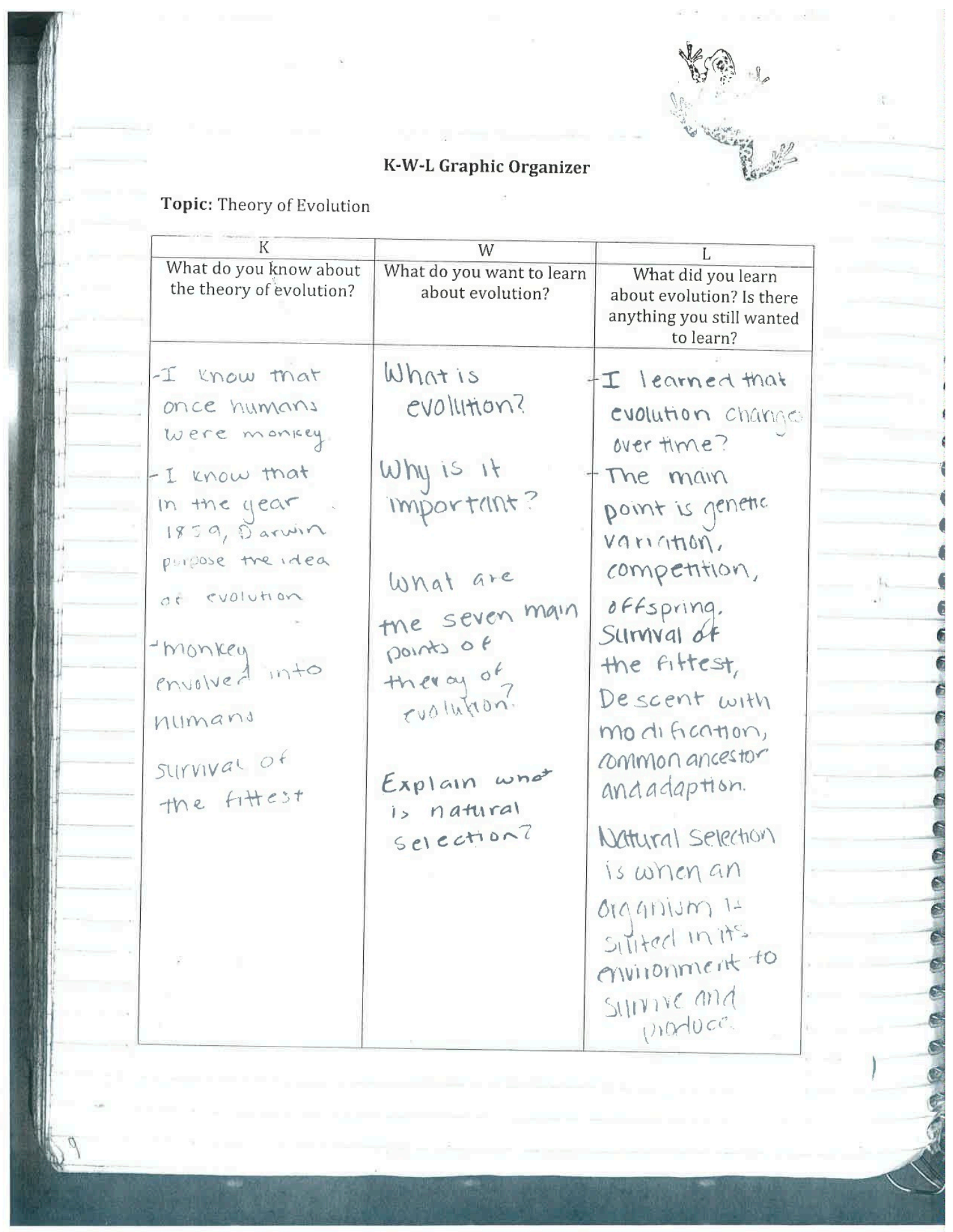




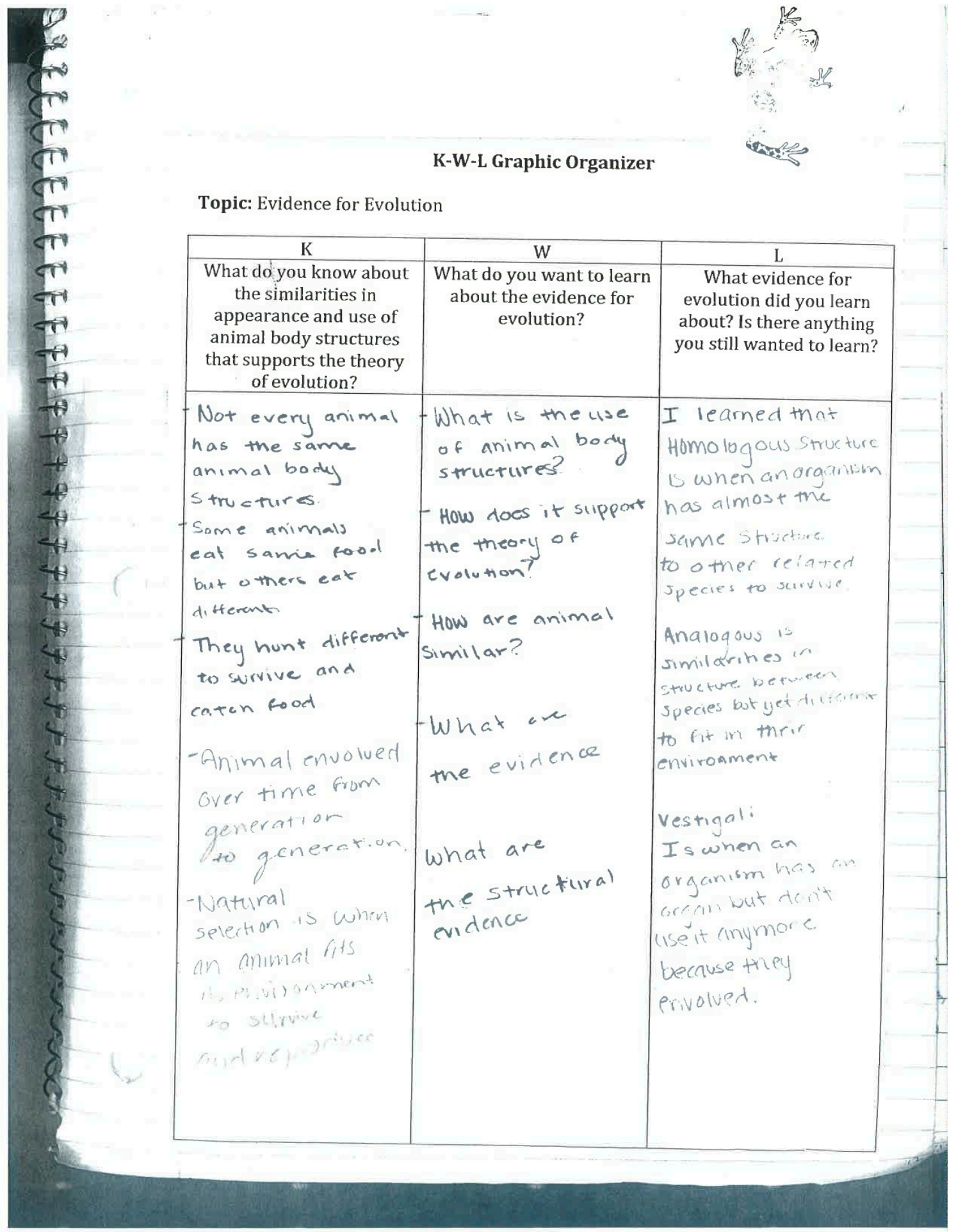




$$
\text { April 28,14 }
$$

K-W-L Graphic Organizer

Topic: Human Evolution

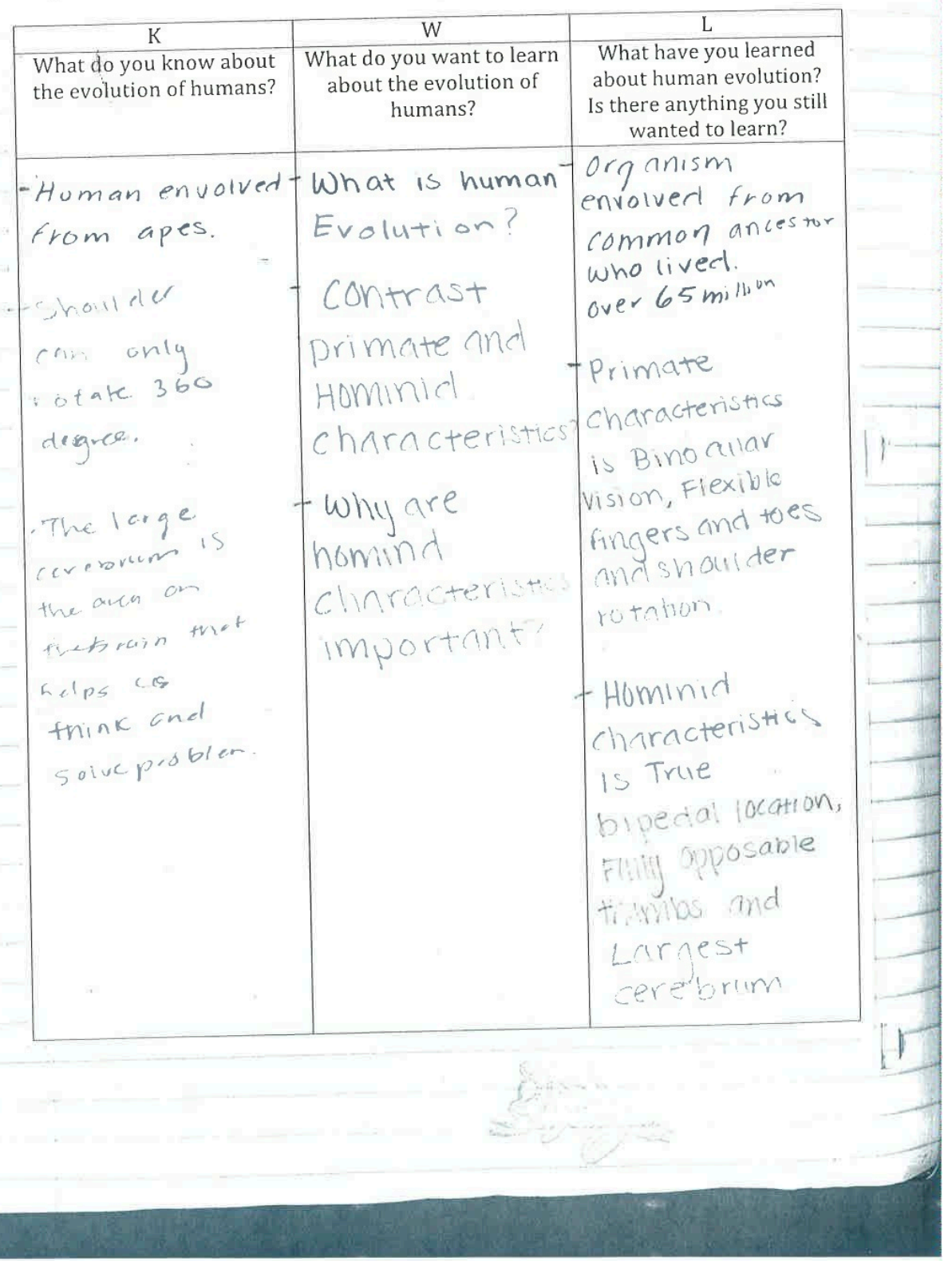


K-W-L Graphic Organizer

Topic: Theory of Evolution

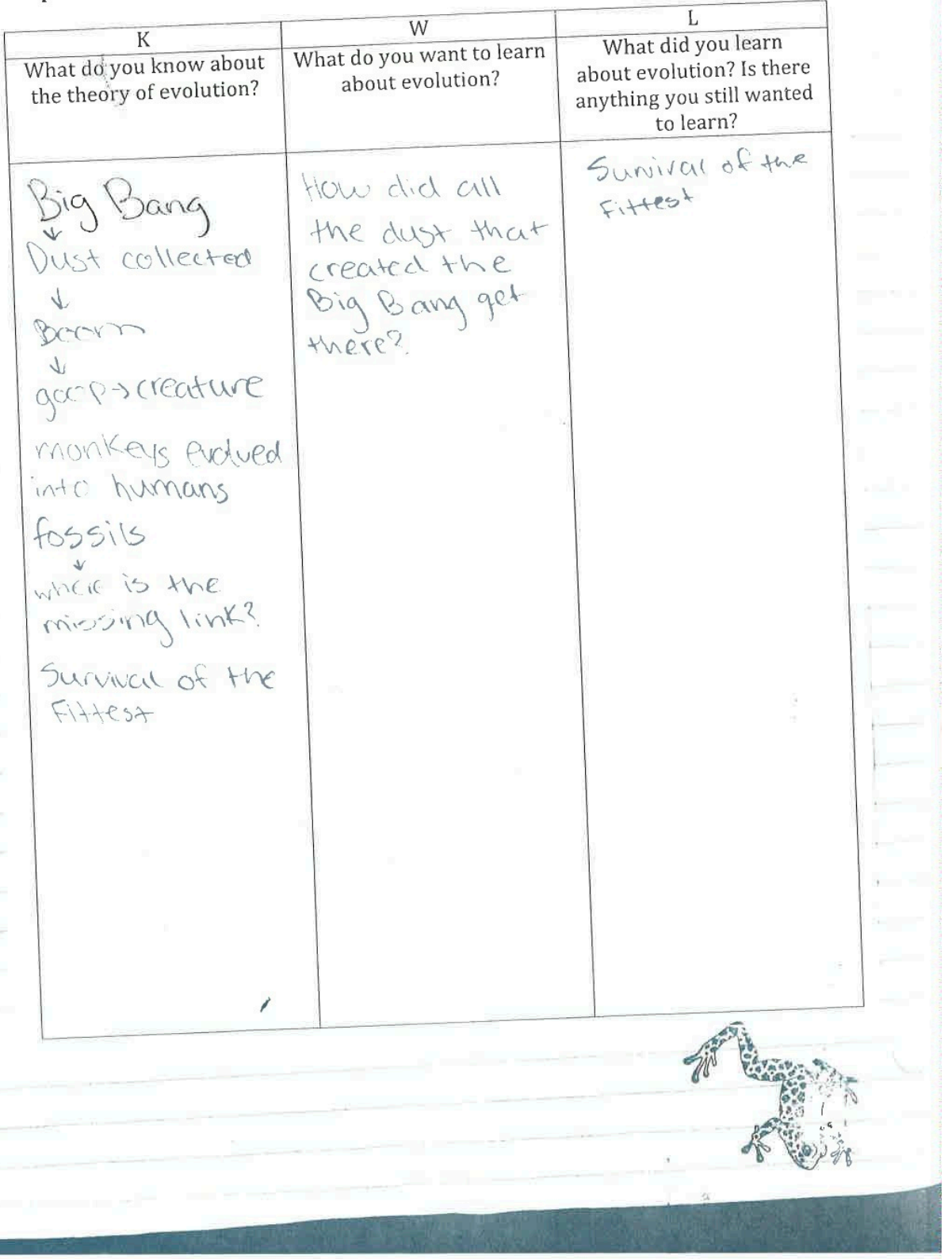




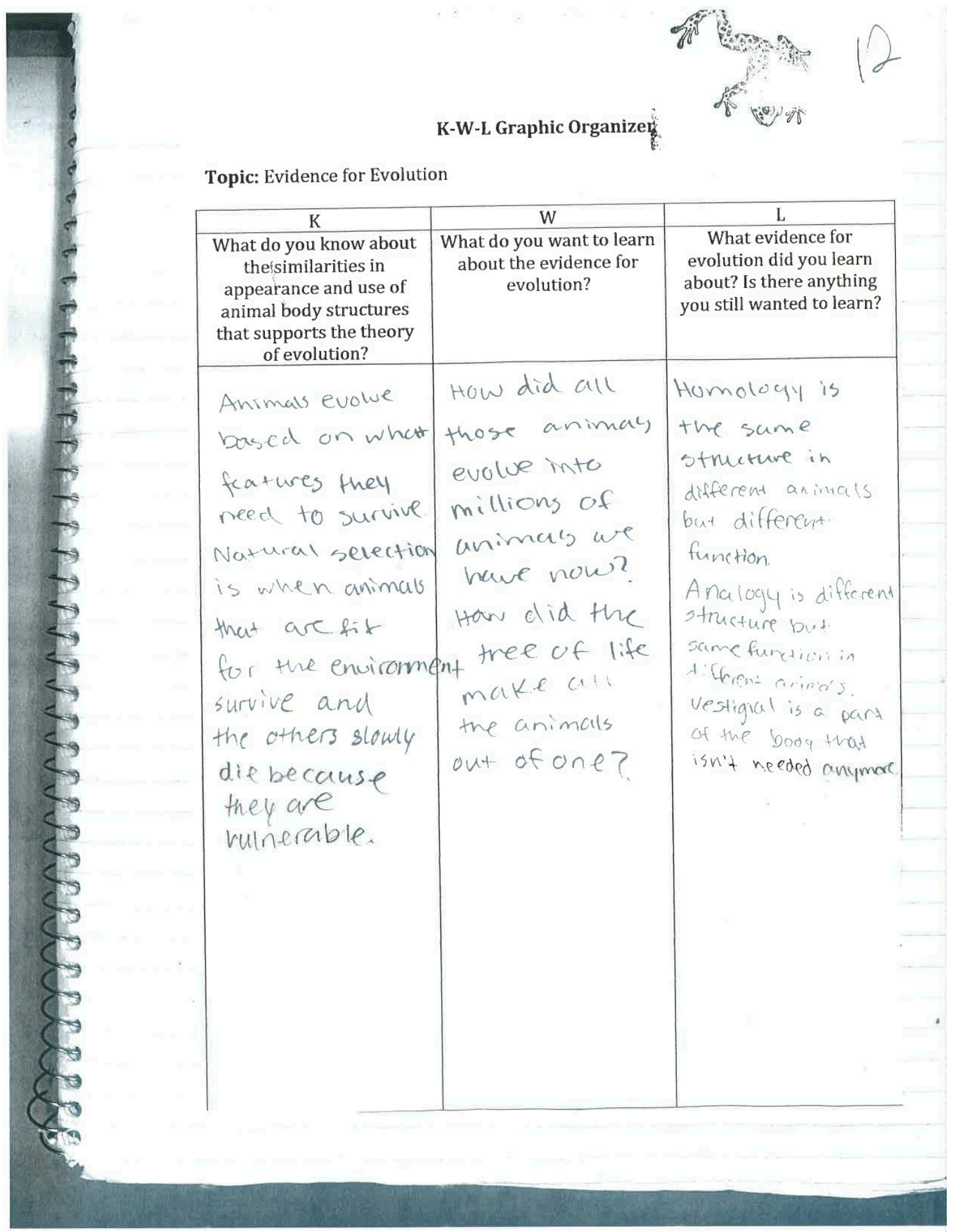




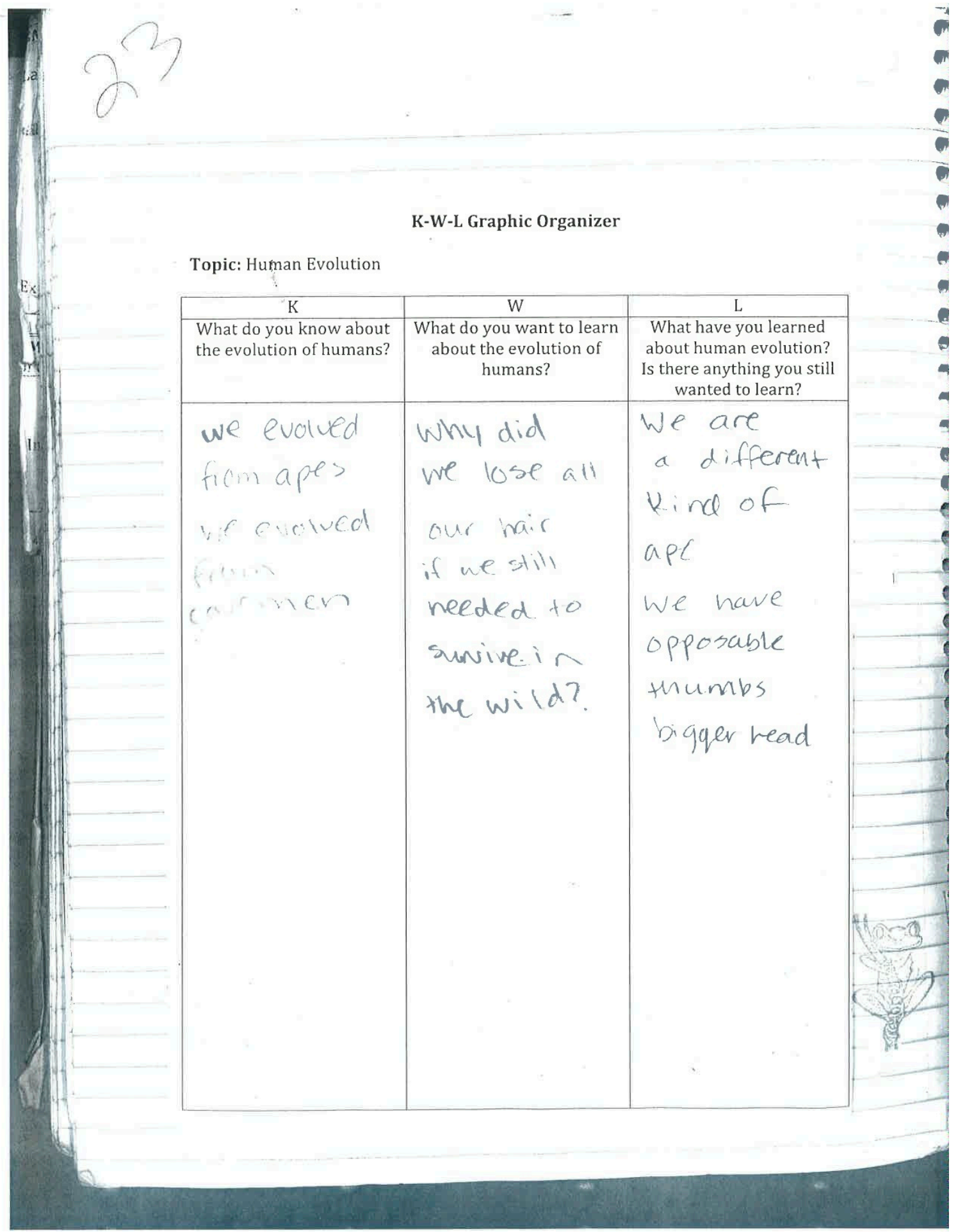




\section{Free Writing Journal Entries}

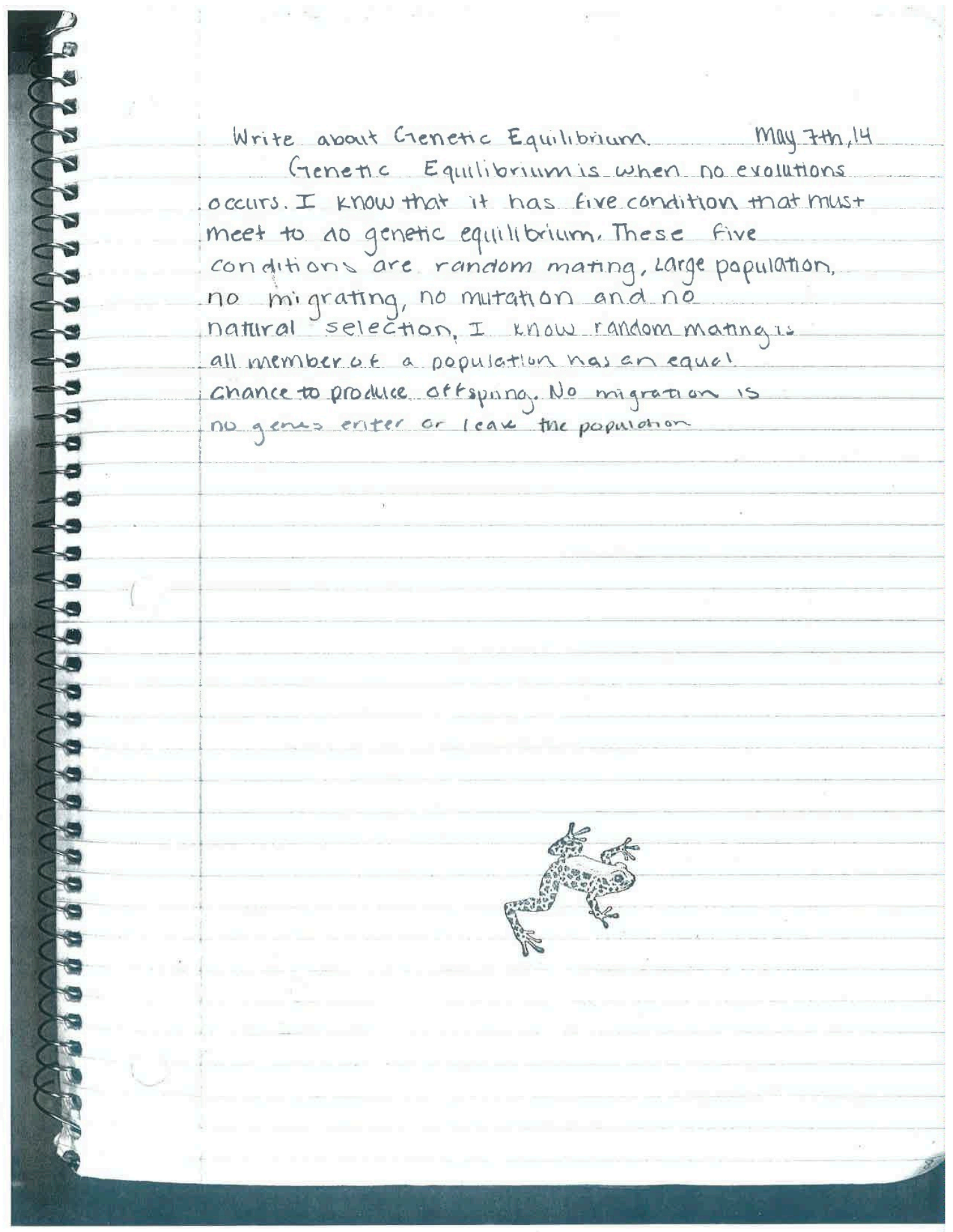




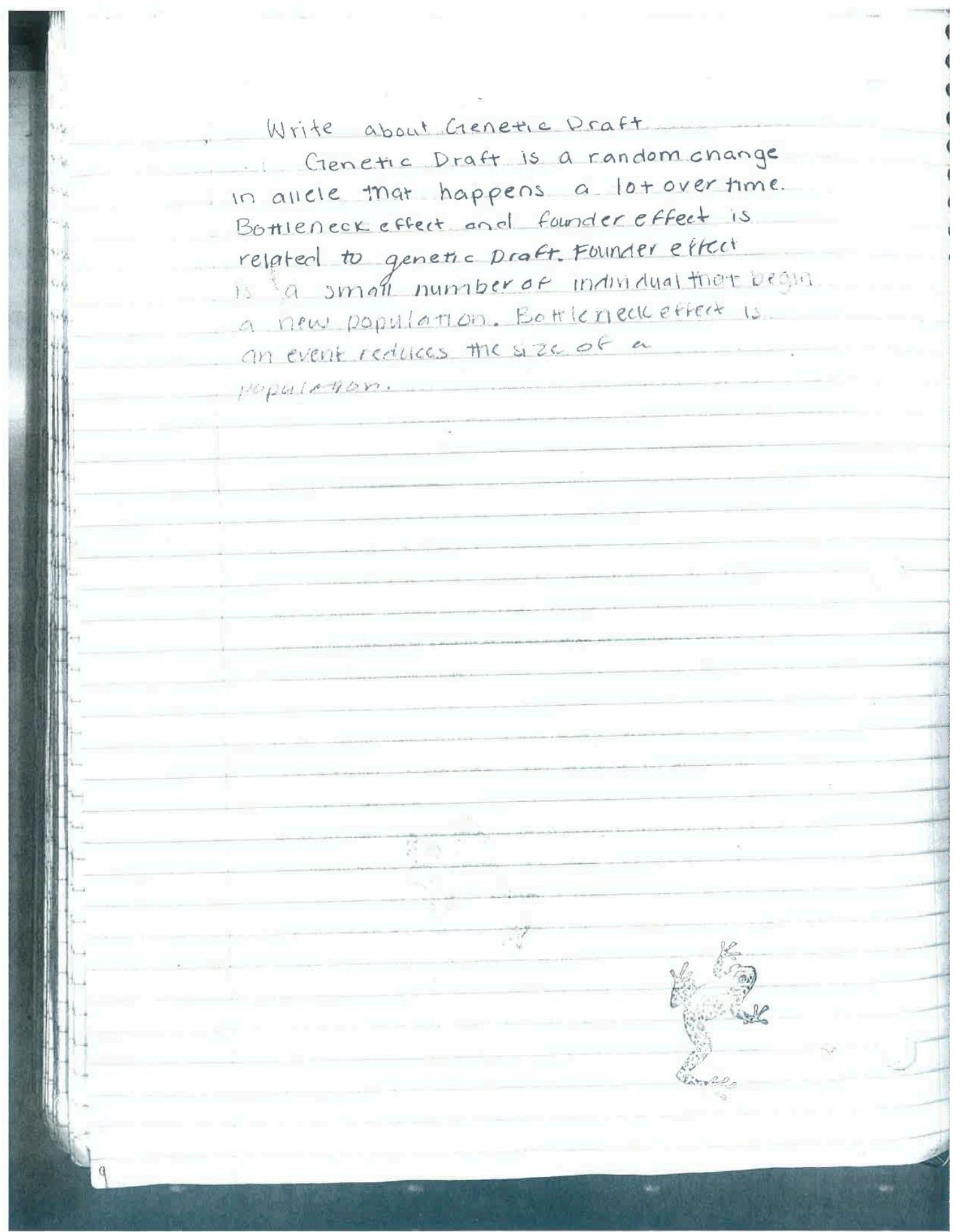




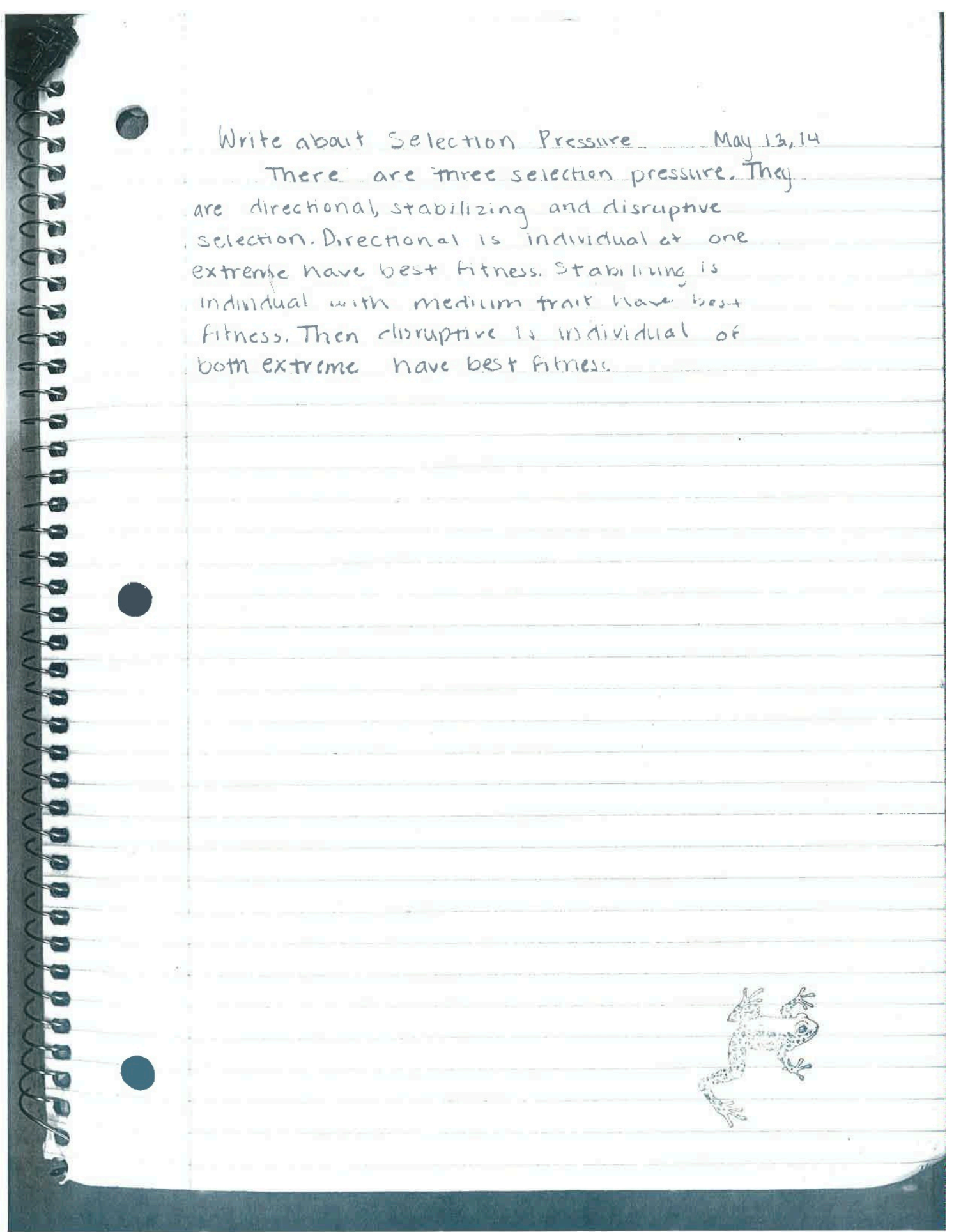


Write about Genetic Equilibrium

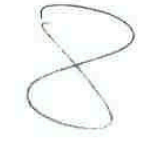
Genetic equitibrium is when the gene alleles remain the same because the population does not change. No individuals come or leave. All individuals have an equal chance to mate. There are no mutations, no migrating, there's a large population and no natural selection because no trait is favored. 


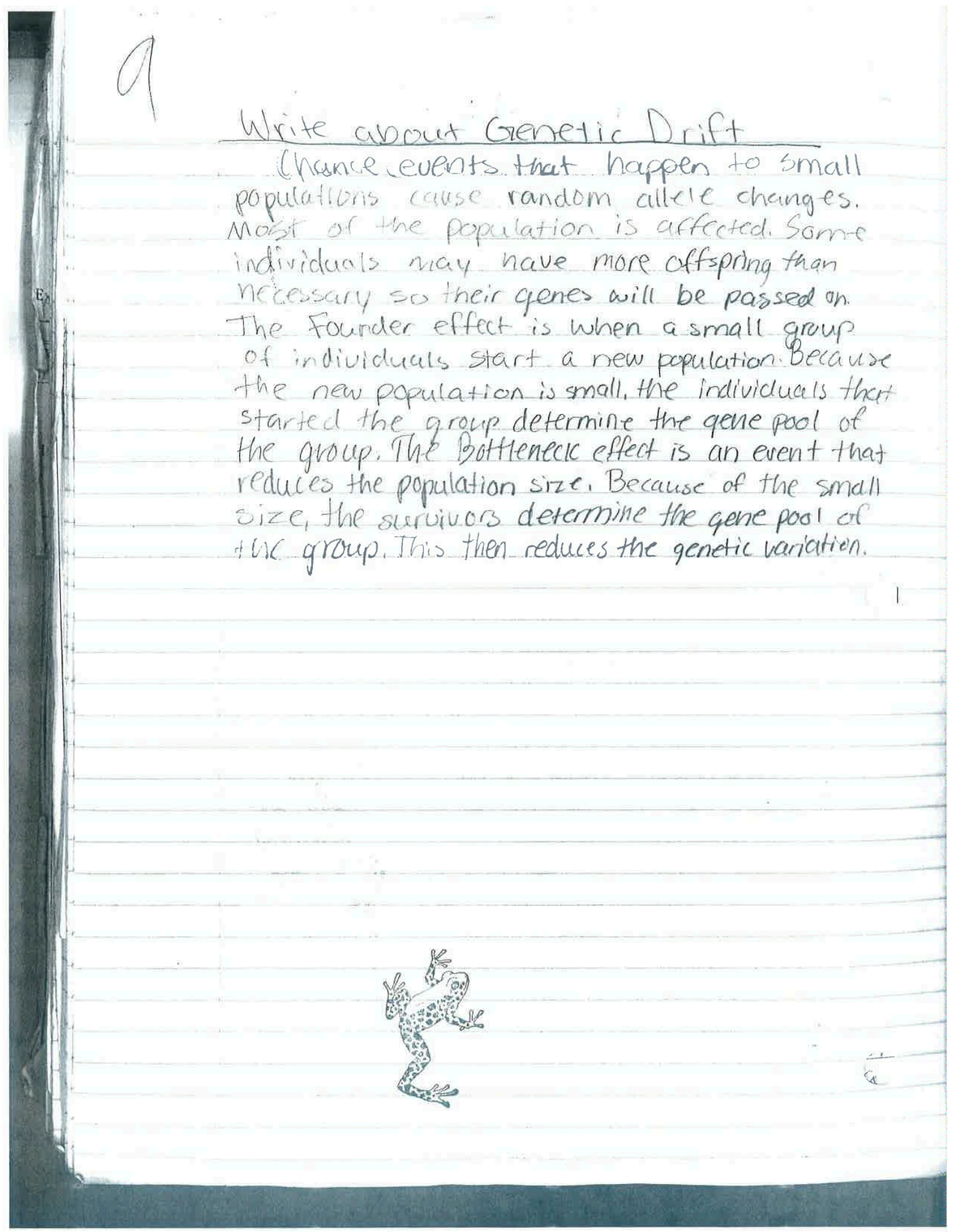




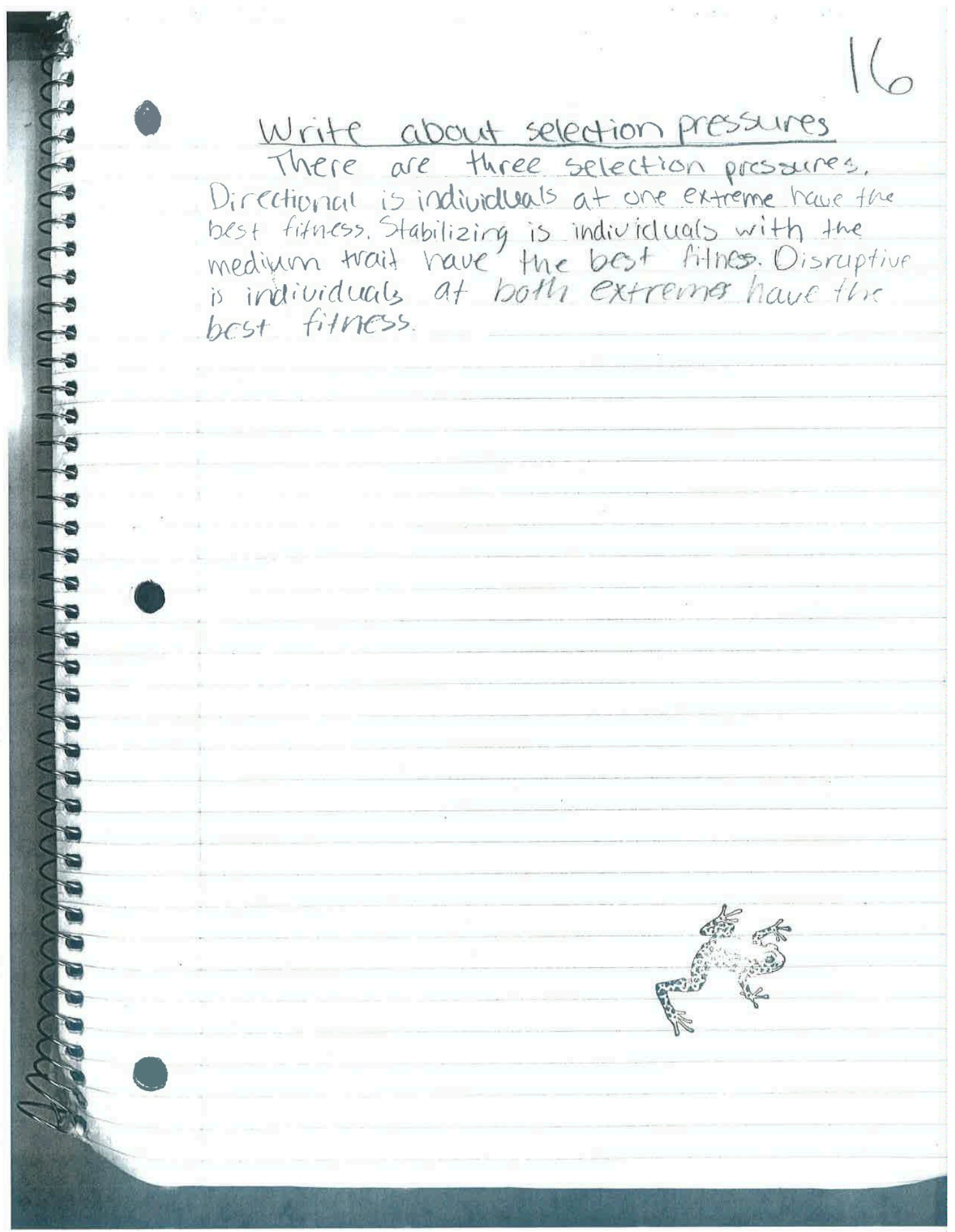




\section{Student Survey Response Notes}

\begin{tabular}{|c|c|}
\hline Student Code & Student Response \\
\hline $\begin{array}{l}\text { Student A } \\
111307\end{array}$ & $\begin{array}{l}\text { - Liked the strategy } \\
\text { - Saw every K-W-L as a review of material } \\
\text { - Liked how it was step by step } \\
\text { - "Every one felt like a pretest for every lesson" }\end{array}$ \\
\hline $\begin{array}{l}\text { Student B } \\
021107\end{array}$ & $\begin{array}{l}\text { - No } \\
\text { - Never looked or thought about the strategy after completing } \\
\text { it }\end{array}$ \\
\hline $\begin{array}{l}\text { Student C } \\
012003\end{array}$ & $\begin{array}{l}\text { - "Didn't really help me out." } \\
\text { - L step did help recall information } \\
\text { - K and W steps didn't } \\
\text { - Wasn't sure what questions to ask because it was new } \\
\text { - "Thaterial } \\
\end{array}$ \\
\hline $\begin{array}{l}\text { Student D } \\
201403\end{array}$ & $\begin{array}{l}\text { - } \quad \text { "Yes, it did." } \\
\text { - } \quad \text { Made student reread and identify what he didn't know } \\
\text { - Helped ask questions } \\
\text { - Helped recall information }\end{array}$ \\
\hline
\end{tabular}

Question 2: Was being provided with question prompts better than simply being asked to free write about the subject? Why/ why not?

\begin{tabular}{|l|l|l|}
\hline Student Code & Student Response \\
\hline Student A & - & Preferred prompts \\
111307 & - & More organized \\
& - & Easier to follow \\
\hline Student B & - & Better with questions \\
021107 & - Had never used before \\
& - Would rather have K-W-L than free write \\
\hline Student C & - "I liked the free write over the prompts." \\
012003 & - "[Free writing] helped more." \\
& - Open writing made you remember for yourself the key points \\
\hline Student D & - "Questions better." \\
201403 & - "Better with chart." \\
& - Outline what he learned before. \\
& - Allowed him to ask, get help, learn, and then repeat process. \\
&
\end{tabular}




\begin{tabular}{|c|c|}
\hline \multicolumn{2}{|c|}{$\begin{array}{l}\text { Question 3: Would you ever think about using the KWL strategy on your own? Are } \\
\text { you likely to use it in the future? Why/ why not? }\end{array}$} \\
\hline Student Code & Student Response \\
\hline $\begin{array}{l}\text { Student A } \\
111307\end{array}$ & $\begin{array}{l}\text { - } \text { Maybe } \\
\text { - Had used it before in AVID and maybe Freshman year } \\
\text { physical science }\end{array}$ \\
\hline $\begin{array}{l}\text { Student B } \\
021107\end{array}$ & - Probably never use it again \\
\hline $\begin{array}{l}\text { Student C } \\
012003\end{array}$ & $\begin{array}{l}\text { - Would use the free writing more } \\
\text { - Had used the K-W-L before in algebra and statistics }\end{array}$ \\
\hline $\begin{array}{l}\text { Student D } \\
201403\end{array}$ & $\begin{array}{l}\text { - Had not used it before } \\
\text { - After being taught to use it he used a variation of it in global } \\
\text { studies and English. } \\
\text { - Student would write down what he knew and "what I don't } \\
\text { understand" in the margins of his notes. Then ask the teacher } \\
\text { those questions. He set it up like a T-chart, similar to just } \\
\text { using the K and W steps of the K-W-L. } \\
\text { "Have trouble understanding teacher sometimes." }\end{array}$ \\
\hline
\end{tabular}

Question 4: Is there anything else you would like to add about using this strategy?

\begin{tabular}{|l|c|}
\hline Student Code & Student Response \\
\hline $\begin{array}{l}\text { Student A } \\
111307\end{array}$ & $\bullet$ L step (what did you learn?) part was the most helpful part \\
\hline $\begin{array}{l}\text { Student B } \\
021107\end{array}$ & $\bullet$ No \\
\hline $\begin{array}{l}\text { Student C } \\
012003\end{array}$ & $\bullet$ No \\
\hline $\begin{array}{l}\text { Student D } \\
201403\end{array}$ & $\bullet$ "Don't think you need the L step." \\
\hline
\end{tabular}

Question 5: You were observed using the K-W-L format in your journal writing although it was no longer required, why was that?

\section{Student Code $\quad$ Student Response}

\begin{tabular}{l|ll}
\hline Student B & - Didn't realize he was using the K step in his free writing
\end{tabular} 021107 journal entries.

- Thought it was interesting 


\section{Appendix C: Revised K-W-L Recommendation}

\section{K-W-L-Q Graphic Organizer}

Topic: Theory of Evolution

\begin{tabular}{|c|c|c|c|}
\hline $\mathrm{K}$ & W & $\mathrm{L}$ & $Q$ \\
\hline $\begin{array}{l}\text { What do you know } \\
\text { about the theory of } \\
\text { evolution? }\end{array}$ & $\begin{array}{c}\text { What do you want } \\
\text { to learn about } \\
\text { evolution? }\end{array}$ & $\begin{array}{l}\text { What did you learn } \\
\text { about evolution? }\end{array}$ & $\begin{array}{l}\text { What additional } \\
\text { questions do you } \\
\text { have about } \\
\text { evolution? }\end{array}$ \\
\hline & & & \\
\hline & & & \\
\hline & & & \\
\hline & & & \\
\hline & & & \\
\hline & & & \\
\hline & & & \\
\hline & & & \\
\hline & & & \\
\hline & & & \\
\hline & & & \\
\hline & & & \\
\hline & & & \\
\hline & & & \\
\hline & & & \\
\hline & & & \\
\hline
\end{tabular}




\title{
Appendix D: Research Approval Documents
}

\author{
Assent/Consent Form \\ Integrating $\mathrm{K}-\mathrm{W}$-L prompts into science journal writing: Can simple \\ question scaffolding increase student content knowledge?
}

You or your child has been asked to participate in a research study in the field of education conducted by Brandon J. Wagner from Portland State University. In partnership with Portland State University, the Portland School District, and Parkrose High School, the purpose of this study is to improve science instruction and provide an opportunity for an enriching experience for you or your child.

The researcher hopes to learn how a teaching method might influence students' understanding of science. This study is being done in partial fulfillment of the requirements for a Master's degree under the supervision of William Becker, Ph.D. You or your child was selected as a possible participant in this study because of his/her enrollment in Kerryn Henderson's honors biology at Parkrose High School.

All students enrolled in the class will participate in the same learning activities. This study will analyze student work collected during four weeks of instruction. By signing this assent/consent form, you or your child give permission for you or your child's work to be analyzed. The student, or your child may also be asked to be interviewed by the researcher. These interviews will not be video or audio taped. Instead the researcher will simply make written notes of student responses linked to specific student assigned codes as to maintain student confidentiality. Any information that is gathered by this study and that can be linked to you/your child or identify you/your child will be kept confidential. This information will be kept confidential by replacing students' names with unique identification numbers. All information will be stored in a locked cabinet, or password-protected electronic format.

The benefits of this study outweigh the less than minimal risks. This study proposes to use a K-W-L literacy strategy. This strategy could improve student understanding of the biology content and potentially raise their class performance and engagement level. Providing the K-W-L strategy to students would provide them the opportunity to become fully versed in a new tool with which to learn content. The K-W-L encourages students to think about a subject before they learn about it and outline what they knew before. Students then judge how new information fits into their understanding of the material.

Further benefits include the possible future use of this strategy should it be helpful to students. This would inform my own teaching and these students continuing use of K-W-L. 
This study is a collection and analysis of information for a method that all students present will be receiving. Students in the study already use science journals in class, which include some portions of science writing. Meaning the possible risk for using the K-W-L method instead of another is very minimal.

Further possible risks in this research may include students' nervousness of the researcher reviewing student work. This risk is minimized by the fact that the researcher has served as a student teacher to the possible participants since the beginning of the 2013-2014 school year. While student teaching the researcher has already seen and graded student work. For this research the investigator will simply be maintaining responsibilities already expected of him. As has already been implemented as a student teacher, the researcher will take all possible steps to maintain student information confidentiality to assuage student concerns.

You/your child's participation is voluntary. He/she does not have to take part in this study, and it will not affect your/his/her final grade or relationship with the teacher or with Portland State University. Also, you may withdraw your permission for you or your child to participate from this study at any time. Likewise, your child may withdraw his/her consent at any time.

If you have questions or concerns about your or your child's participation in this study, contact Brandon J. Wagner at (660) 287 - 4853. If you have concerns about your or your child's rights as a research subject, please contact PSU Office of Research Integrity, 1600 SW $4^{\text {th }}$ Ave., Market Center Building, Ste. 620, Portland, OR 97207; phone (503) 725-2227 or 1 (877) 480-4400.

Thank you for considering this request.

Sincerely yours,

Brandon J. Wagner

Please keep this page for your records. 


\section{Assent/Consent Form}

Please sign this page and return it to Mrs. Kerryn Henderson.

Your signature indicates that you have read and understand the above information and agree to let you or your child's work be analyzed as part of this study. You or your child will participate in classroom activities regardless of the inclusion of their work in the study. The researcher will provide you with a copy of this form for your own records.

Signature of Student

Date

Print name of Student

Signature of Parent/Guardian

Date

Print name of Parent/Guardian 


\section{Application for Human Subjects}

\section{Investigator's Assurance (To Be Attached)}

\section{II. Project Title \& Prospectus}

This study will attempt to answer the research question: To what extent can the use of K-W-L prompts in science journal writing increase students' content knowledge? Using a quasi-experimental design, two high school biology classes will study the same content unit. The treatment group will be asked to use learning journals supplied with K-W-L prompts covering different sections of the unit. These questions will address what the students knew $(\mathrm{K})$ about the topic before the lesson, what information the students want (W) to know about the topic, and finally what the students learned (L) from the class session. This group of students will be given explicit directions on how the journal entries should be written and to consider how each topic relates to any information from the previous lessons so as to promote a cyclic approach to learning. Students in the comparison group will also receive journals, but they will only be asked to write about what information was covered in class. Both groups will be directed to write their entries as if relating information to a peer or individual unfamiliar with the material. After the first unit has been completed and assessed the experimental group and comparison group will be switched. This second iteration will allow the new treatment group exposure to the K-W-L strategy, of which they were previously deprived, while the new comparison group will be instructed to write about the class material, but given no restriction on how to format the information. A different, yet equally challenging unit of biology will be utilized as the content material for this new trial. 
The students will also be given a pre and posttest during the study. This will determine whether or not the K-W-L strategy provided an advantage. Post trial student interviews of eight to ten students in the experimental group will be conducted in order to gather qualitative information. This qualitative data will record student impressions of the strategy and whether they plan to use the strategy in the future. Student interviews of the second comparison group will also be conducted to ascertain whether the K-W-L strategy was implemented for the second set of journal entries when no direct format was required.

\section{Level of Risk to Subjects}

The students will be subjected to less than minimal risk. Students participating in this study will already be expected to use interactive journals as outlined and provided by their current high school biology teacher. This study merely asks the research subjects to answer additional questions within the K-WL format. These questions will pertain to activities and content already apart of their normal academic requirements.

Students will be randomly chosen to participate in a posttest interview. These interviews will be conducted away from other students to mitigate any stress or chances of embarrassment for the subject. Questions asked during these interviews will be limited to their impressions, use, and likelihood to continue using the K-W-L format on their own. At the end of the interview the participants will be given the opportunity to provide any additional comments they feel are important to note. 
Student confidentiality will be maintained throughout the study. Students will be given codes in order to match their test scores and K-W-L journal writing samples. These codes will also be needed in order to sample which students will be interviewed. Because of this only the researcher will know the true identity of the student participants ensuring their confidentiality and minimizing risk of exposure of student work and interview responses.

\section{Subject Recruitment}

The classes participating in the study will be selected because both will be of the same level of biology, within the same school, and taught by the same instructor. Students asked to participate in the study were non-randomly assigned to one of two classes chosen because the researcher has no control over class enrollment. Each class will consist of 25-35 students totaling a maximum of 70 students for the study. Members of the classes will be between 13 to 16 years of age and at the $10^{\text {th }}$ grade level. It is expected that the gender ratio will be as close to $1: 1$ as possible. Students of varying ethnicities will be included in the study.

Because this research does not specifically address the needs of students with special education or English language learning needs, the researcher will not have access to those students' records to identify them as requiring special needs. Instead the cooperating teacher will help monitor the implementation of the intervention in order to make sure the researcher addresses all accommodations and modifications. 
Since all students will be receiving this intervention regardless of receiving the students' or their parents' signed approval, each will be subjected to the same instructional experience within the cooperating teacher's classroom guidelines. Meaning students that receive failing grades will be given the opportunities as seen sufficient by that of the cooperating teacher to make up assigned work and receive the appropriate credit for high school Honors Biology.

\section{Informed Consent}

Student consent will be obtained through the use of signed consent forms. This form will be sent home with students in their science journals. Parents and students will be encouraged to read the form and chose whether or not to participate in the study. This form will explain how participating in the research will in no way influence the student's final grade in honors biology. The student and family's identities will be kept private and safe guarded. These safeguards include the use of password-protected devices for any documents in digital form and a locked cabinet for any hard copy materials. The consent form will include contact information for the researcher if at any time the family has questions or concerns about the research. Finally, the students choosing to participate in the study will return the consent forms with their signature, their parent's signature, and date of said signatures. 


\section{First-Person Scenario}

While taking a high school honors biology class I was asked to participate in a research project by my teacher and student teacher. After my parents and I signed a consent form I was given a pretest about information we had not covered yet. Then I was given extra journal pages for the interactive learning journal I already use for biology. These pages provided questions based on the material we were going to cover in class. I was to complete the first two questions before class then the last question after class. These were to be completed twice a week for the entire unit. Mr. Wagner gave us explicit directions on how the answers to the questions should be written. After the unit was completed and we'd taken the unit test, Mr. Wagner interviewed myself and a couple other students about writing these special journal entrees. He asked if we felt they helped us learn the material and whether we'd attempt to use them again on our own.

\section{Potential Risks and Safeguards}

This study is a collection and analysis of data for an experience that all students present will be receiving. Student participants in the study already use interactive science journals, which include some portions of science writing. Meaning the possible risk for implementing the educational intervention proposed instead of another strategy is very minimal.

Further possible risks in this research may include students' apprehensiveness of the researcher reviewing student work. This risk is minimized by the fact that the researcher has served as a student teacher to the possible 
participants since the beginning of the 2013-2014 school year. In this student teaching capacity the researcher has already been exposed to and graded student work, providing constructive feedback as needed. For this research the investigator will simply be maintaining responsibilities already expected of him. As has already been implemented as a student teacher, the researcher will take all possible steps to maintain student information confidentiality to assuage student concerns.

The benefits of this study outweigh the less than minimal risks. Enriching student understanding of biology content can potentially raise their class performance and engagement level. Providing the K-W-L strategy to students would provide them the opportunity to become fully versed in a new tool with which to learn and evaluate content. The K-W-L encourages students to think about a subject before they explore it and outline what they know previously. Students then evaluate how new information fits into their mental schema, altering or correcting previous misconceptions.

Further benefits include the possible future use of this strategy should it show to be beneficial to students. This would inform my own teaching and these students continuing implementation of K-W-L.

\section{Potential Benefits}

Students participating in this study will be exposed to a literacy strategy they may not have used otherwise. The K-W-L format allows students to form connections between materials and puts students in a pre and post learning mindset about course content. Using these extra journal entrees will also grant the students 
more time to engage with the content and practice writing and communicating information. All of which are valuable skills and preparation for their unit tests. Students may also be more likely to utilize such a strategy on their own with future material without prompting. It is the stance of this research that students using the $\mathrm{K}-\mathrm{W}$-L question strategy will also perform better on unit tests.

By providing a simple question structure students can be invited to become active participants in their learning through identifying what they still need to learn and how any new information fits into their understanding of the topic. This strategy can be retooled to align to any area of content and works great as an introduction to a new unit. The flow of the questions also acts as an organizer for student ideas concerning the subject.

\section{Confidentiality, Records \& Distribution}

Student identities will be kept confidential through the use of individual and randomly assigned code numbers. These codes will be used for any gathered documents, such as test scores or K-W-L graphic organizers. Corresponding student identities for these codes will be stored in a locked cabinet on the PSU campus located in the Center of Science Education. Any digital or scanned documents will be kept on a password-protected computer used only by the researcher. Any transportation of documents will be conducted by the researcher alone and will be locked away during transit. The one key held by the researcher and another by the researcher's advisor. 


\section{Portland State University Institutional Review Board Approval}

503-725-2227 tel
$\begin{array}{ll}\text { Post Office Box } 751 & \text { P03-725-8170 fax } \\ \text { Portland, Oregon 97207-0751 } & \begin{array}{l}\text { Committee } \\ \text { hsrrc@lists.pdx.edu }\end{array}\end{array}$
Human Subjects Research Review

Date: April 09, 2014

To: $\quad$ Melissa Potter / Brandon Wagner

From: Karen Cellarius, HSRRC Chair

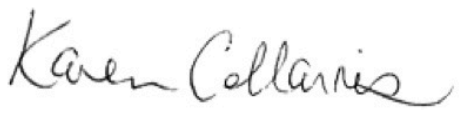

Re: $\quad$ HSRRC approval for your project titled, "Integrating K-W-L Prompts Into Science Journal Writing: Can Simple Question Scaffolding Increase Student Content Knowledge?" HSRRC Proposal \# 132868

Approval-Expiration: April 09, 2014 - April 08, 2015

Review Type: Expedited, Categories 6,7

In accordance with your request, the PSU Human Subjects Research Review Committee has reviewed your request for approval of the project referenced above for compliance with PSU and DHHS policies and regulations covering the protection of human subjects. The Committee is satisfied that your provisions for protecting the rights and welfare of all subjects participating in the research are adequate, and your project is approved. Please note the following requirements:

Approval: You are approved to conduct this research study only during the period of approval cited above; and the research must be conducted according to the plans and protocol submitted (approved copy enclosed).

Consent: Signed consent is required from all participants in this study.

Changes to Protocol: Any changes in the proposed study, whether to procedures, survey instruments, consent forms or cover letters, must be outlined and submitted to the Committee immediately. The proposed changes cannot be implemented before they have been reviewed and approved by the Committee.

Continuing Review: This approval will expire on 04/08/2015. It is the investigator's responsibility to ensure that a Continuing Review Report on the status of the project is submitted to the HSRRC two months before the expiration date, and that approval of the study is kept current. The Continuing Review Report is available at www.rsp.pdx.edu/compliance_human.php and in the Office of Research and Strategic Partnerships (RSP).

Adverse Reactions and/or Unanticipated Problems: If any adverse reactions or unanticipated problems occur as a result of this study, you are required to notify the Committee immediately. If the issue is serious, approval may be withdrawn pending an investigation by the Committee.

Completion of Study: Please notify the Committee as soon as your research has been completed. Study records, including protocols and signed consent forms for each participant, must be kept by the investigator in a secure location for three years following completion of the study (or per any requirements specified by the project's funding agency).

If you have questions or concerns, please contact the Office of Research Integrity in the PSU RSP at 503-725-2227. 